\title{
SENTIMIENTO Y VALOR
}

Con frecuencia se ha confundido el sentimiento con el valor. Pues si bien siempre se ha establecido una estricta distinción entre el hecho y el valor (siempre ha sido evidente que lo que había de valorarse eran los hechos), la escuela positivista, a partir de Hume, identificó el sentimiento y el valor. Sin embargo, el sentimiento no es más que un hecho interno y está sujeto a valoración justo igual que un hecho externo. Ambos, el hecho externo y el interno, son el material en bruto que, al ser organizado, se convierte en valoración.

La valoración del hecho externo consiste en ver tres aspectos distintos del hecho, a saber, 1) simbolizado, 2) observado y clasificado y 3) experimentado de modo inmediato. El hecho, según estos tres aspectos, parece tener tres clases distintas de propiedades, a saber, propiedades primarias, secundarias y terciarias respectivamente. Tales propiedades se relacionan de acuerdo con la regla que dice que las propiedades primarias son respecto a las secundarias lo que éstas respecto a las terciarias. Dado que sabemos, por la historia de la ciencia, cuál es la relación entre las propiedades primarias y las secundarias, esta regla nos permite no sólo inferir la relación entre las propiedades secundarias y las terciarias, sino determinar también las propiedades terciarias, tradicionalmente llamadas propiedades de valor. Por medio de lo que puede llamarse la generalización axiológica, extendemos la noción de valor a las otras dos clases de propiedades - las primarias y las secundarias - y consideramos así a las tres clases de propiedades como pro piedades de valor. Después damos el nombre de propiedades de valor sistémico a las primarias, el de propiedades de valor extrínseco a las secundarias, y el de propiedades de valor intrínseco a las terciarias. Surgen, así, tres dimensiones del valor, sistémico, extrínseco e intrínseco, que se refieren a las cosas que poseen las respectivas clases de propiedades.

De este modo puede examinarse la valoración de los hechos externos. Una vez que se la entiende se puede proceder al análisis de la valoración de los hechos internos o sentimientos.

\section{Valoración y hecho externo (efecto)}

a) Efecto, afecto y valor. Los hechos son aquello con lo que se inicia la valoración. Son, como dijimos, el material que ha de ser organizado por la valoración. En todas las situaciones, los hechos y los valores están tan estrechamente entremezclados que se necesita un esfuerzo especial para distinguirlos. Pongamos un ejemplo sencillo: si ruedo escaleras abajo, me lastimo. 
El rodar escaleras abajo es un hecho externo, un efecto, el lastimarme es un hecho interno, un afecto. Ninguno de ellos es un valor. Ambos, sin embargo, vistos desde el especial punto de vista valorativo, pueden convertirse en valores. La valoración es una operación específica efectuada sobre estos hechos: puedo "enfurecerme" conmigo mismo por haber olvidado asegurar el tapete o aun enfurecerme con las escaleras. En ambos casos llevo a cabo un acto de valoración o, para ser más exactos, de desvaloración ya sea de mí mis. mo o de las escaleras. Pero el enfurecimiento, como emoción, no entra en la valoración, es un hecho interno adicional, que acompaña la valoración. Ésta consta de lo siguiente: a) "Fui un descuidado al no asegurar el tapete." b) "Las escaleras no sirven. Hay que arreglarlas." Y, con cierta sutileza axiológica, consideraré el rodar escaleras abajo como c) una aplicación equivocada de la ley de la gravedad. Se trata de tres diferentes complejos de valor. a) Es una desvaloración (extrínseca) de mí mismo como dueño de casa; $b$ ) es una desvaloración (extrínseca) de las escaleras en cuanto escaleras; c) es una desvaloración (sistémica) de mí mismo. Cada uno de estos complejos de valor tiene su propia fórmula de valor.

Estos complejos de valor difieren de los efectos y afectos que los llevan o acompañan, el rodar escaleras abajo, la herida física, y el enfurecimiento conmigo o con las escaleras. Por otro lado, puede haber heridas no físicas que son valores y que expresamos al decir: "Me siento herido." Tal herida no es nunca física. Me siento herido cuando alguien me desvaloriza, pero no cuando ruedo las escaleras. En este último caso, me hiero o lastimo. En "me siento herido", la palabra "siento" es usada en un sentido valorativo - ejemplo de la confusión entre emoción y sentimiento que permea nuestro lenguaje. Mi sentirme herido va acompañado por una emoción, pero no es una emoción. La emoción que acompaña a mi sentirme herido no es un valor sino un afecto. "Sentirme herido" es la desvaloración (intrínseca) por mi parte de una desvaloración (intrínseca) de mí mismo hecha por otro. A su vez, este complejo de valor tiene su fórmula y es tratado en la axiología, pero la emoción al sentirme herido -el sentimiento de "sentirme herido"es un asunto psicológico.

Podemos variar el ejemplo. Digamos que un niño rueda las escaleras, se lastima, llora, recibe unas nalgadas y llora de nuevo. Su rodar las escaleras es un hecho externo. Su dolor físico es un hecho interno, su llanto por su dolor físico es otro hecho interno, las nalgadas que recibe son tanto una acción mecánica como un hecho externo, el llanto del niño por las nalgadas es un hecho interno. Pero todos estos hechos tienen sus aspectos de valor: a) el rodar las escaleras es una desvaloración gravitacional del niño; $b$ ) su llanto por su dolor físico es una desvaloración de este dolor, c) las nalgadas que recibe son una desvaloración de su conducta que le llevó a rodar las escaleras, su llanto por las nalgadas recibidas es, en parte $d$ ), una desvalora- 
ción de su dolor, pero de un dolor distinto al de rodar las escaleras, y en parte $e$ ) un llanto no por el acto mecánico de recibir unas nalgadas, sino por el acto moral de recibirlas como una desvaloración de símismo, lo mismo que f) una desvaloración de mamá que da nalgadas. Así, su llanto por las nalgadas es una estructura de valor mucho más complicada que su llanto por rodar las escaleras. En total hay seis complejos de valor unidos en este pequeño caso.

Pasaremos ahora a ampliar este ejemplo. Si la mamá dice: "Te he dicho que no debes jugar en el barandal y te voy a dar unas nalgadas para que lo recuerdes", el acto valorativo de dar unas nalgadas recibe una explicación de hecho que el niño comprenderá fácticamente: "Es peligroso jugar en cl barandal, porque puede uno caerse" o "Si juego en el barandal, podré caerme". Y concluye fácticamente: "Por lo tanto no jugaré (no debo jugar) en el barandal". Todos éstos son juicios fácticos, excepto en la medida en que implican una desvaloración del jugar en el barandal. (Las palabras "jugaré", "debo", en sí mismas no significan una valoración. Sólo tienen este significado cuando están en un contexto valorativo. Así, "todos los círculos deben ser redondos" no es un enunciado valorativo sino fáctico.)

El niño, y aun los adultos, tendrán dificultades para separar los aspectos valorativos de una situación de los afectivos ( $y$ aun de los aspectos de efecto). Pero conforme avanza el pensamiento racional, así lo hace la capacidad de distinción. Pasado algún tiempo, la madre puede observar que el niño juega de nuevo en el barandal. Le dirá: "Juanito, tno te acuerdas ya de lo que te pasó la última vez que jugaste en el barandal?", y él se volverá a verla y dirá: "Sí, sí me acuerdo." "Entonces, ¿por qué juegas de nuevo ahí? ¿Quieres volver a lastimarte?" El niño mueve la cabeza. "¿No sabes que te queremos y no deseamos que te lastimes?" El niño asiente. "Entonces, ¿por qué haces lo que no debes?" Responde: "No lo sé." “¿No tienes conciencia?", pregunta la mamá. El niño asiente. "¿No te duele la conciencia cuando haces algo malo?" Asiente de nuevo. "¿Dónde te duele?", pregunta la madre. $\mathrm{Y}$ entonces Juanito se llevará la mano hacia atrás, recordando las nalgadas. No ha aprendido aún a distinguir entre el hecho externo, el interno y la valoración. La madre esperaba que se pusiera la mano sobre el corazón y dijera: "La conciencia me duele aqui", pero esto sería pedir de. masiado de Juanito, quien no ha aprendido aún a abstraer el aspecto valorativo de una situación y a darle una localización metafórica. Piensa aún en forma concreta, al igual que los pueblos primitivos (como los nativos africanos que esperaban que la Libertad llegase por tren); y localiza los valores en efectos externos, como lo hace el pensamiento mágico de los primitivos. El localizar los valores internamente es un logro muy abstracto (acentuado, por ejemplo, por Jesús, cuando dijo: "Dios está en vosotros".) Y el comprender que tal localización es meramente metafórica y no real y separar, en 
consecuencia, el contenido valorativo de su localización interna o emocional es aún más difícil (no se ha logrado hacerlo aún del todo ni siquiera en la teoría del valor). Así, en tanto que el niño confunde el valor y el efecto (su conciencia y la parte física que se usó para recordárselo), los adultos confunden valor y afecto (la conciencia y su "localización interna", "en el corazón", "en el alma", etc.). La valoración no está nunca "dentro de nosotros" en un sentido espacial. Es una organización especifica de datos (efectos y afectos), que producimos mediante nuestra capacidad racional: una operación especifica que llevamos a cabo con nuestro entendimiento sobre los efectos y los afectos. Así, producimos, respectivamente, valores extrínsecos e intrinsecos.

Así, pues, la valoración es una cosa y otra muy distinta los hechos internos y externos. Hasta ahora los hemos separado por medio de ejemplos, esto es, en la práctica. Pero ahora debemos separarlos metodológicamente, es decir, en teoría, considerando el análisis valorativo como un método de conocimiento preciso. En tal teoría, los hechos y los valores aparecen en forma diferente a como aparecen en la práctica. Al describir los valores experimentados en las situaciones prácticas hablamos como valoradores; al analizar tales valores hablamos como analistas del valor. De la misma manera que los hechos analizados son diferentes de los hechos experimentados, así los valores analizados son diferentes de los valores experimentados. Lo que ahora debemos hacer es definir estas diferencias. Examinaremos primero la diferencia entre el efecto y su análisis, y después la del afecto y su análisis. Este procedimiento nos ayudará, por una parte, a aclarar la distinción entre dos clases de hechos (externos e internos) y, por la otra, las dos clases correspondientes de valores (extrínsecos e intrínsecos).

b) Efecto y efecto analizado. La relación entre Efecto y Efecto Analizado (o entre Hecho Externo y Hecho Externo Analizado) es la más fácil de describir por ser materia de conocimiento común. Ha sido descrita con gran detalle desde principios de la era cientifica, tanto por científicos practicantes como por filósofos de la ciencia. Pues el hecho externo es la materia propia de la ciencia natural y su análisis es la ciencia natural misma. Así, el tema de esta sección se reduce a describir el aspecto fundamental de la ciencia natural, la relación entre el hecho externo y su análisis científico.

Si bien esto se ha hecho muchas veces antes, es importante repetirlo aquf por dos razones.

Primera, porque las relaciones paralelas -entre hecho interno y hecho interno analizado- son todo menos obvias y sólo pueden ser aclaradas mediante una referencia a la conocida relación entre hecho externo y su análisis científico. Segunda, porque las relaciones que vamos a describir son, en sí mismas, relaciones de valor. Sirven para distinguir las diversas dimensiones. del valor. En resumen, las relaciones en cuestión son las siguientes: 
El análisis del hecho externo es, respecto a éste, lo que el hecho externo es respecto al valor extrinseco.

El análisis del hecho interno es, respecto a éste, lo que el hecho interno es respecto al valor intrinseco.

Análisis del Hecho Externo: Hecho Externo = Hecho Externo: Valor Extrínseco

Análisis del Hecho Interno: Hecho Interno $=$ Hecho Interno: Valor Intrínseco o

\begin{tabular}{|c|}
\hline Análisis del Hecho Externo \\
\hline Hecho Externo \\
\hline Valor Extrínseco \\
\hline
\end{tabular}

\begin{tabular}{|c|}
\hline Análisis del Hecho Interno \\
\hline Hecho Interno \\
\hline Valor Intrínseco \\
\hline
\end{tabular}

En general

\begin{tabular}{|c|}
\hline Análisis del Hecho \\
\hline Hecho \\
\hline Valor
\end{tabular}

Esto significa que tenemos tres niveles: análisis del hecho, el hecho mismo y el valor. El hecho sirve, en una forma que ha de determinarse aún, para el análisis del valor. El Hecho es Valor Analizado. Así, pues, los tres niveles son:

\begin{tabular}{c}
\hline Análisis del Hecho (Hecho Analizado) \\
\hline Hecho $\rightarrow$ Análisis del Valor (Valor Analizado) \\
Valor
\end{tabular}

Dado que el análisis del hecho (o hecho analizado) es la ciencia natural, y el análisis del valor (o valor analizado) es la ciencia moral, el cuadro de la parte superior significa los tres niveles siguientes:

\begin{tabular}{|c|}
\hline Ciencia Natural \\
\hline Hecho $\rightarrow$ Ciencia Moral \\
\hline Valor
\end{tabular}


Lo que quiere decir que el Hecho debe ser organizado, en alguna forma, de tal modo que sirva como análisis del valor (o valor analizado), es decir, como constituyente estructural de la ciencia moral.

Una ciencia consta de elementos que deben ser diferentes de la materia de dicha ciencia. Así, pues, si la materia de la ciencia natural es el hecho, la ciencia natural misma no puede constar de hechos. Debe constar de simbolos del hecho. El libro de la naturaleza, dice Galileo, "está escrito en lenguaje matemático y los símbolos son triángulos, círculos y otras figuras geométricas". ${ }^{1}$ ¿Cómo sacó Galileo los símbolos a partir de los hechos? En sus experimentos analizó los hechos hasta llegar a sus últimos elementos (llamados "simples" en la terminología de Descartes) y descubrió que éstos correspondian a ciertos símbolos de las matemáticas. Después manipuló estos símbolos de acuerdo con su lógica inherente - la de las matemáticas- y constituyó esta última como lógica de los hechos. Así, a través de sus experimentos, descubrió que la velocidad de un cuerpo en movimiento es igual al espacio que recorre en un cierto tiempo, dividido por el tiempo, $\mathrm{v}=\frac{e}{t}$. Esta línea de división matemática entre $s$ y $t$ fue el descubrimiento de Galileo. Su grandeza no estriba meramente en haber encontrado la línea - ya otros lo habían hecho antes de él一, sino en haber llevado este procedimiento a un punto absoluto, de tal manera que quedó del todo libre de la observación y pudo tomar la línea divisoria, el resultado final de sus ob. servaciones y mediciones, como punto de partida para un procedimiento completamente nuevo y diferente. "Si el resultado de mis observaciones - arguyó - es correcto y la velocidad es igual al cociente de espacio sobre tiempo, no necesito ya de la observación. Este cociente mismo me entregará todas las relaciones entre movimiento, espacio y tiempo que necesito. Todo lo que he de hacer es seguir las leyes matemáticas contenidas en él y sacar de ellas todas las conclusiones posibles. Dado que mi fórmula original me entrega la relación entre espacio, tiempo y movimiento, todas las deducciones hechas a partir de ella deben ser aplicables al espacio, al tiempo y al movimiento; y puedo verificarlas cuando y donde me plazca. De ahora en adelante, ya no haré observaciones a fin de construir leyes, sino que haré leyes para construir observaciones. Usaré mi primer logro, el cociente de espacio y tiempo, como premisa de todo un sistema de deducciones." ${ }^{2}$ Así, pues, pasó a deducir de modo puramente formal todas las relaciones contenidas en su fórmula inicial. Así, si $v=e / t$, luego $v \times t=e$, y si esto último, entonces $e$ es un rectángulo con los lados $v$ y $t$; y este rectángulo, con los ángulos, triángulos, diagonales, etc., contenidos en él, le sirvió para conocer todo lo que deseaba acerca del movimiento.

1 Opere Complete di Galileo Galilei, 1842 ss., vol. IV, pág. 171.

2 Cf. Discorsi intorno a due nuove Scienze, día cuarto, Proposición VII, Corolatio. 
En otras palabras, Galileo saltó de la observación a la manipulación de símbolos. Saltó del análisis de los hechos a la síntesis de las fórmulas - de la resolución a la composición, según sus propias palabras - y la operación con estas fórmulas le entregó resultados en el terreno del espacio, el tiempo y el movimiento. Esto era natural; pues si la premisa original, la fórmula $v=e / t$, era correcta, todas las deducciones lógicamente correctas hechas a partir de ella tenían que producir resultados correctos acerca de la realidad correspondiente. Así, pues, una vez que los hechos fueron desmenuzados en sus elementos observacionales y se arreglaron estos elementos en la forma de una premisa matemática - la fórmula original-, Galileo pudo usar las deducciones hechas a partir de ella como patrón de los hechos.

Este procedimiento, que tanto éxito ha tenido para lograr una ciencia de los hechos, debe ser accesible, de acuerdo con nuestra premisa, para producir una ciencia de los valores. La ciencia del valor no puede constar de valores, debe constar de simbolos de valores; éstos últimos deben ser desmenuzados hasta llegar a sus elementos y debe descubrirse que éstos corresponden a los símbolos de cierto sistema formal, como por ejemplo algún aspecto de la lógica. Después, estos símbolos deben arreglarse en una fórmula original y esta última debe ser manipulada de acuerdo con sus propias leyes inherentes - las de la lógica en cuestión. En consecuencia, ésta debe quedar constituida como la lógica del valor. La observación de la realidad del valor debe entregarnos la premisa del sistema; los elementos del valor deben ser arreglados en la forma de la fórmula original. Y si esta fórmula es correcta, podrá tomar el lugar de observaciones ulteriores; todas las deducciones que se hagan a partir de ella deberán entregar resultados correctos acerca de la realidad correspondiente. Es el método del análisis y la síntesis, de la resolución y la composición, el que debe producir la ciencia de los valores a partir de éstos. No conocemos otro medio de producir una ciencia.

De acuerdo con el cuadro de la pág. 252, los elementos de los valores son los hechos; por lo tanto son los hechos los que debe descubrirse que corresponden a los símbolos de un sistema formal de valor. En otras palabras, los hechos son los elementos del valor y sirven como constituyentes estructurales de la ciencia del valor (ciencia moral), de la misma manera que las figuras geométricas de Galileo son los elementos del hecho y sirven como material para la ciencia del hecho (ciencia natural). Justo como estas figuras son parte de una estructura formal - la geometría-, así los hechos son parte de una estructura formal - una lógica - que determina el valor, una axiología. Y justo como la estructura formal de los elementos del hecho nos entregó la ciencia del hecho, así la estructura formal de los elementos del valor - los hechosnos entregará la ciencia del valor. La estructura formal que nos entregó la ciencia del hecho era la organización de los elementos de los hechos -figuras formuladas como símbolos geométricos- en la que Galileo transformó sus 
observaciones de situaciones de hecho. La estructura formal que nos entrega la ciencia del valor es la organización de los elementos del valor - los hechos, formulados como símbolos lógicos - en la que la axiología transforma las observaciones de las situaciones de valor. Tales hechos, formulados como símbolos lógicos, son predicados descriptivos. Tal como la organización de figuras, en cuanto símbolos geométricos, representa hechos, así la organización de hechos, en cuanto símbolos axiológicos, representa valores. Esto significa que los hechos son las propiedades primarias del valor. ${ }^{3}$

c) Propiedades primarias y secundarias. Aclararemos ahora esta relación con más detalle. La distinción tradicional entre las propiedades primarias y las secundarias nos ayudará a evadir las muy vagas nociones corrientes de "hecho" y de "valor" y las pondrá bajo un común denominador.

Las propiedades primarias de una cosa son las propiedades de la cosa científicamente explicadas, las propiedades secundarias de una cosa son las propiedades de ella sin explicación (como apariencia o fenómeno). El análisis del hecho consta, en otras palabras, de propiedades primarias del hecho, y el hecho mismo consta de propiedades secundarias del hecho. En forma semejante, las propiedades primarias de un valor (una situación de valor) son las propiedades del valor explicadas cientificamente, y las propiedades secundarias de un valor son las propiedades de éste sin ser explicadas (como apariencia o fenómeno). En otras palabras, el análisis del valor consta de propiedades primarias de valor y el valor mismo consta de propiedades secundarias de valor. Veamos qué significa esto.

Las propiedades secundarias del hecho son propiedades sensibles. El hecho se nos aparece a través de nuestros sentidos. Así, pues, las propiedades secundarias de la mesa sobre la cual escribo son las que veo, toco, huelo, etcétera. Pero sus propiedades primarias son las usadas por las ciencias que tratan de la mesa; las especificaciones del fabricante de la mesa, las medidas del carpintero, etc. (la química orgánica de la madera no pertenece a la ciencia de la mesa, sino a la de la madera). Antes de que la mesa existiera era un conjunto de medidas en la mente del carpintero: " $75 \times 65 \times 125 \mathrm{~cm}$." por lo que respecta al tamaño, " $20 \mathrm{~kg}$ " por lo que respecta al peso y "100 años" por lo que respecta a su supuesta duración. Una vez que la mesa existe, sus medidas son sus propiedades primarias. Las propiedades primarias de una cosa son las que corresponden a sus medidas. En el caso de la mesa, " $75 \times 65 \times 125 \mathrm{~cm}$.; $20 \mathrm{~kg}$; 100 años". Todas las restantes propiedades de la mesa son sus propicdades secundarias. Las propiedades primarias pueden ser separadas de la cosa y representadas por sí mismas, como cuando se dibuja un modelo, un plano, o se establece una fórmula. El plano de una casa, por ejemplo, consta de propiedades primarias, la casa misma consta de propiedades secundarias.

3 Para una exposición más detallada, véase Robert S. Hartman, La estructura del valor, Fondo de Cultura Económica, México-Buenos Aires, 1959, págs. 265-275. 
Las últimas incluyen las primeras - las propiedades de la casa incluyen aque. llas de sus propiedades que corresponden al plano. Éste representa a aquélla -el plano representa la casa. A fin de sacar las propiedades secundarias de las primarias - la casa del plano- tenemos que concretar, es decir, añadir propiedades - tenemos que construir la casa (verter el concreto, etc.); a fin de sacar las propiedades primarias de las secundarias tenemos que abstraer, es decir, restar propiedades, por ejemplo, al hacer el mapa de una región. En el mapa hay muchas menos propiedades que en la región, aun cuando el mapa contiene las propiedades esenciales de la región. El proceso de concreción es un proceso de producción, el proceso de abstracción lo es de reducción.

Pasemos ahora a aplicar todo esto al valor.

El análisis del valor consta de propiedades primarias de valor, el valor mismo consta de propiedades secundarias de valor. El valor puede ser medido y las propiedades dentro del valor que corresponden a la medida son las propiedades primarias del valor. Los valores pueden ser planificados, por reducción, es decir, por abstracción o sustracción de propiedades de valor; y los planos de valor pueden ser convertidos en valores por producción, es decir, por concreción o adición de propiedades de valor.

La relación entre el valor y el hecho, mencionada más arriba, quiere decir que siempre que hablamos de propiedades primarias de yalor, podemos hablar de propiedades secundarias de hecho. Puesto que decir -como lo hemos hecho- que el hecho es un valor analizado es lo mismo que decir que las propiedades secundarias del hecho son las propiedades primarias del valor.

Por ello, todas las relaciones mencionadas entre las propiedades primarias y las secundarias pueden aplicarse a la relación entre hecho y valor: el hecho representa el valor; el valor incluye el hecho. El hecho es el valor abstraído; el valor es el hecho concretizado. El hecho es el valor sustraído; el valor es el hecho adicionado. El hecho es la reducción del valor; el valor es la producción del hecho. El hecho es el valor medido; el valor es el hecho usado como medida.

La llamada concreción del hecho, por ejemplo, la casa, no es pues toda la concreción que existe. La concreción implica algo más que la concreción del hecho; existe la concreción más plena del valor. La casa, en cuanto valor, es más concreta que la casa en cuanto hecho. Los sentidos sólo nos entregan la concreción de los hechos. Los valores no se nos presentan a través de los sentidos; sólo las propiedades primarias del valor se presentan a los sentidos - porque son hechos. El valor mismo, al ser más rico en propiedades que el hecho, debe presentársenos a través de una capacidad que pueda aprehender una realidad más rica que la que aprehende la experiencia sensible. Los planos del valor, por ello mismo, deben ser más plenos que los planos del hecho; ya que los planos del valor son hechos. Podemos decir que los hechos no 
son sólo los planos, sino que son las huellas del valor -las huellas en el mundo espacio-temporal de los sentidos. Los planos de los hechos - la ciencia natural-son los planos de los planos de valor. Así, pues, si los planos del hecho constan de propiedades primarias y el hecho mismo de propiedades secundarias, las propiedades de valor, como propiedades secundarias de propiedades secundarias, pueden ser llamadas propiedades terciarias.

Así, pues, decir que el análisis del hecho es respecto a éste lo que el hecho es respecto al valor, significa que:

I. Las propiedades primarias son, respecto a las secundarias, lo que éstas respecto a las terciarias.

II. Las propiedades terciarias son, respecto a las secundarias, lo que éstas respecto a las primarias.

Procedamos ahora a explicar todo esto por medio de un ejemplo. Supongamos que un agrimensor recorre una cierta región con el fin de hacer el mapa de ella. En su primer viaje, lo único que hará será ver lo que lo rodea y tomar notas mentales - y reales - de cómo proceder. Este primer viaje es una observación fáctica del paisaje; lo mira, lo escucha, quizá hasta lo huele y, en general, lo siente, es decir, hace uso de sus sentidos a fin de aprehenderlo ampliamente, en su totalidad dada. En los viajes sucesivos, será más selectivo: tratará de encontrar aquellos lugares más adecuados para sus propósitos de agrimensor, haciendo primero una lista general y reduciéndola gradualmente al mínimo de lugares necesarios esenciales para levantar el mapa de la región en consideración. Estos lugares finales son los esenciales de la región para los propósitos de un mapa.

El proceso total es de reducción, de disminución de una totalidad percibida y aprehendida, a sus pocos esenciales. El primer viaje puede estar contenido en un Informe que es una descripción directa de la región. Puede llevar el título de: "Descripción de la Región X". Los viajes subsecuentes pueden estar contenidos en un Informe que es una exposición o programa de cómo intenta actuar el agrimensor en su tarea de encontrar los puntos esenciales para la medición. Su Informe puede titularse: "Exposición de Posibles Lugares de Agrimensura en la Región X”. Los lugares finalmente elegidos, quizá no más de una docena tomada de centenares de posibilidades, pueden estar contenidos en un Informe titulado: "Definición de la Región X por los puntos A-K"

Los tres pasos, descripción, exposicion y definición son los pasos lógicos universales que preparan una cosa para su explicación científica. Son pasos de reducción, de concreción sucesivamente disminuida, pero también de ignorancia sucesivamente disminuida. Con la definición, la cosa no queda aún explicada científicamente. Es su preparación para el análisis científico. Pues el análisis habrá de llevarse a cabo sobre estạ definiçión. Lạ región científica- 
mente explicada - y representada - es el mapa. La región definida en términos de lugares de agrimensura no es el mapa; pero sí es el punto de partida para hacer el mapa. La cosa, tal como aparece en estos tres pasos - descrita, explicada y definida-, es la cosa sin explicación, pero preparada para ella. Todos estos pasos tratan con las propiedades secundarias, con las propiedades sensibles. Las propiedades secundarias son, como hemos visto, las propiedades de la cosa inexplicada en el sentido científico; pero cada uno de estos pasos tiene menos y menos propiedades tales. La definición, con el conjunto mínimo de propiedades secundarias, es la cosa preparada para su transformación en una cosa de propiedades primarias —n nuestro caso, el mapa.

Así, pues, la descripción, la exposición y la definición son conjuntos de propiedades secundarias. Aun la definición contiene propiedades sensibles, si bien en forma abstracta; en tanto que la descripción enumera estas propiedades concretamente. El proceso que va de la descripción a la definición puede llamarse, pues, un proceso de concreción a abstracción. La definición es ese conjunto mínimo de proniedades secundarias que son necesarias y suficientes para caracterizar la cosa. Es una descripción mínima. Y la caracterización y la descripción no son, en un sentido estricto, explicaciones cientificas de su asunto. Esta es la diferencia entre, por ejemplo, Linneo y Darwin. Linneo describe y define, clasifica y caracteriza. Darwin explica. Propone un único principio que ordena todo el reino biológico. Añade a los hechos observados y clasificados, descritos y definidos, un principio creador de explicación. Esta adición creadora sólo puede hacerse cuando todo el campo ha sido ordenado previamente por la secuela de los pasos que van de la descripción, a través de la exposición, hasta la definición.

Como hemos visto, cada uno de estos pasos contiene menos propiedades que el que lo antecede. La definición contiene menos propiedades que la exposición y ésta menos que la descripción. Esta última es el conjunto con el mayor número de propiedades secundarias, la definición es el conjunto con el número menor -el mínimo- de tales propiedades. Así, cada secuela de la descripción, la exposición y la definición es un conjunto de un conjunto-depropiedades, el uno incluye el otro, que conducen al conjunto mínimo, la definición. Son como tres volúmenes que estuvieran incluidos unos en otros. El proceso de abstracción es semejante a un cono que tuviera la descripción en la base, la definición en el ápice y la exposición en su centro.

Dado que la abstracción de una cosa puede hacerse en infinidad de modos, una cosa es, en realidad, una infinidad de tales conos. Es decir, los tres pasos de la descripción, la exposición y la definición pueden seguirse uno a otro según un número infinito de líneas. Un ingeniero minero que pasara por la misma región que el agrimensor daría un conjunto de descripción, exposición y definición completamente diferente; un ecólogo a su vez otro del todo diferente; y un general otro también diferente. Así, pues, existe 
para cada cosa un número infinito de conjuntos de descripción, exposición y definición. Puesto que cada uno de estos conjuntos consiste en una secuela de conjuntos-de-propiedades, que se incluyen mutuamente, y cada una de las cuales lleva a una definición, podemos decir que en cada caso existe un número infinito de conjuntos de conjuntos-de-propiedades-secundarias que llevan a un número infinito de definiciones. Esto significa que hay una infinidad de conjuntos de aspectos sucesivamente menores de una cosa, cada uno de los cuales lleva a sus respectivos aspectos mínimos, a saber, las definiciones.

Pero el proceso no se detiene en la definición. Como hemos visto, la cosa definida no es la cosa explicada y representada científicamente. Aunque abstraída sigue siendo la cosa misma. La cosa científicamente explicada y representada no es la cosa en cuanto definición, sino en cuanto simbolo. Es la cosa formalizada.

Pero volvamos al agrimensor. La región científicamente explicada es la región en cuanto mapa, es decir, la región formalizada y simbolizada. La región como mapa es, desde luego, una cosa diferente de la régión definida por los puntos "A-K". Es el resultado de una operación efectuada sobre estos puntos, a saber, la operación agrimensora misma. Esta operación formaliza la región. Y en la formalización - el mapa- encuentra su culminación la obra del agrimensor. Los tres pasos conducen lógicamente hacia la formalización. Pero, si bien estos pasos son prerrequisitos para la formalización no tienen que llevar necesariamente a ella. El agrimensor puede considerar que es imposible levantar un mapa de esa región, que los lugares son inaccesibles o inconvenientes, y puede recomendar un procedimiento diferente, por ejemplo, medir desde el aire. En este caso, su medición se detuvo en las primeras etapas, nunca llegó a su meta, el mapa.

El procedimiento de medición es una ilustración perfecta de actividad intelectual y de la producción de una ciencia en particular. Así, las observaciones de Galileo corresponden a los viajes de medición; los resultados de sus observaciones a los sitios de medición "A-K"; su fórmula a la operación real de medición con teodolitos, etc., que es un procedimiento completamente nuevo y puramente formal, usando los lugares como puntos de partida para operaciones geométricas; y el mapa como totalidad de los símbolos que representan la región corresponde a la mecánica galileana como un sistema desarrollado a partir de la fórmula. Y así como el agrimensor puede tener que detenerse antes de alcanzar su meta y contentarse con unas cuantas observaciones, lo mismo puede ocurrirle a muchos científicos.

En el caso del agrimensor, la ruptura entre las dos partes de su procedimiento, la material y la formal, la observativa y la geométrica, es especialmente evidente. Es obvio que hay un salto a un procedimiento del todo nuevo, de la selección de lugares en la región dada a la medición geométrica y al cálculo con instrumentos precisos. En investigacionnęs más abstractas no 
resulta tan claro; aun en el caso de Galileo, algunos intérpretes han visto sólo una actividad, ya sea la observativa o la geométrica. Y en el caso de los valores la distinción entre las dos actividades es aún más difícil -y necesaria.

La dificultad surge del hecho de que las dos actividades, si bien van juntas, están separadas por un abismo infranqueable. La observación y la abstracción pertenecen al mundo de los sentidos, la formalización al mundo del intelecto. No hay continuidad alguna entre ellas -y sin embargo son parte de un mismo y único proceso. Ambas, la unidad y la distinción, se nos presentan claramente en el caso del agrimensor. El proceso de formalización de la Región X es la medición de ella por medio de instrumentos -alidadas, teodolitos, taquímetros, etc.-, la delineación de los resultados de esto sobre el papel y, finalmente, el dibujo e impresión del mapa. Como ya hemos dicho, el mapa es la región formalizada, la región como símbolo. Es la región cientificamente explicada y representada. El mapa tiene propiedades, pero son más bien propiedades primarias que secundarias. Así, pues, las propiedades primarias son, como hemos dicho, las propiedades de la cosa formalizada, es decir, cientificamente explicada y representada. Así, la cosa inexplicada y la cosa cientificamente explicada, la región y el mapa, son completamente diferentes y, sin embargo, se corresponden estrechamente. Están conectadas por una relación de simbolización - la relación entre la cosa simbolizada y el símbolo que la simboliza. ${ }^{4}$

Lo que es verdadero respecto al procedimiento del agrimensor, lo es respecto al del ingeniero minero, el ecólogo y el estratega. Todos estos procedimientos culminarán en mapas; y todos estos mapas pueden ser combinados en uno solo que muestra los descubrimientos del ingeniero minero, los del ecólogo y los del estratega delineados sobre el mapa del agrimensor. En esta forma se combinan los diferentes aspectos de la región en una sola formalización; todos ellos tienden a un mismo y único resultado ideal: el mapa total de la región. En consecuencia, el mapa final es el resultado total de todos los diferentes aspectos combinados en un simbolismo bidimensional o conjunto de símbolos. Este mapa final con todos los símbolos que contiene es a lo que se reducen todos los aspectos.

Si bien no hay una continuidad de procedimiento entre el proceso de abstracción - la elección de lugares-, por una parte, y el de formalización —l levantamiento del mapa-, por la otra, ambos son uno solo y se corresponden en la relación simbólica. El procedimiento de abstracción es el prerrequisito para el procedimiento de formalización, y este último es la culminación del primero. Así, como dijimos más arriba, la abstracción y la formalización forman una unidad, aun cuando estén separadas por un abismo infranqueable.

4 Esta relación ha sido investigada por Ernst Cassirer, en especial en su Philosophie der symbolischen Formen. Véase, por ejemplo, el vol. III, Berlin, Bruno Cassirer Verlag, 1929 , págs. 251 ss: 
Un proceso que lleva a una meta que, sin embargo, está separada del proceso por un abismo insalvable es llamado un proceso limite. Tales procesos no son infrecuentes en la vida diaria - por ejemplo, dos rieles, a pesar de ser paralelos, parecen convergir en la distancia, pero el punto de convergencia está infinitamente lejos. Son muy comunes en el pensamiento y las matemáticas los definen muy claramente. En matemáticas, un límite es "un valor o forma fijo al cual puede acercarse un valor o forma variable, pero sin alcanzarlo nunca". Por ejemplo, la expresión $\frac{x}{x}$ muestra un "valor o forma variable" en el denominador, $x$. En tanto $x$ varia de valores inferiores a superiores, toda la expresión se aproxima a un valor fijo, a saber, cero. Sin embargo, nunca llegará a cero, por alto que sea el denominador. A fin de alcanzarlo es necesario saltar mentalmente más allá del proceso hasta su meta ideal. En la misma forma, el punto hacia el cual convergen las dos paralelas nunca será alcanzado por ellas -aunque el pensamiento continúa lo que el proceso no puede hacer-, extiende el proceso hasta el infinito y encuentra ahi su meta ideal, una meta intelectual solamente. El punto en consideración sólo se alcanza en el pensamiento, por el salto del pensamiento de lo finito hacia lo infinito. Así, el punto es un mero punto de pensamiento o punto ideal. Y cero, en cuanto límite de $\frac{I}{x}$, es también un mero punto ideal, pues mientras $\frac{I}{x}$ sea un proceso final no alcanzará el cero y para alcanzarlo el proceso tiene que saltar hacia la infinitud, lo que no puede hacer en cuanto proceso final. $\mathrm{O}$ bien, tómese el caso de una esfera de la que se dice que toca un plano en un solo punto. Esto no ocurre nunca así en la experiencia; una esfera toca un plano en un plano. Pero meramente en el pensamiento, lo toca en un punto. ${ }^{5}$ La geometría, como ciencia ideal del espacio o ciencia del espacio ideal, nada tiene que ver con los sentidos; aun cuando los objetos cuya representación formal es la geometría deben pertenecer necesariamente a los sentidos. Pero sus propiedades geométricas son meras propiedades ideales; son sus propiedades primarias con respecto al espacio -y en la geometría einsteiniana, no euclideana, también con respecto al tiempo.

Dado que los objetos pueden ser vistos desde una infinidad de aspectos diferentes, pueden tener propiedades primarias con respecto a una infinidad de aspectos. En cualquier aspecto, las propiedades primarias son los límites de un proceso de abstracción observativa. Este proceso lleva, por pasos finitos, de la descripción a la definición. De ahí continúa, por medio de un salto al infinito, hacia la formalización. Ésta es la reducción infinita de la definición. Transforma la definición en una fórmula.

5 Cf. Galileo Galilei, Opere I, págs. 224-226; VII, págs. 158-160. 
La formalización origina la estructura pura de la cosa en cuestión. Es la cosa como estructura ideal. Esta estructura puede ser representada en un simbolismo bidimensional: como letras, números, círculos, triángulos o mapas.

El mapa representa la estructura pura de la Región X. No es esta estructura pura. La estructura pura misma está sólo en la mente del geómetra (o quizá de Dios, si Dios es, como sostuvieron Platón y Leibniz, un geómetra). Esta estructura pura es el límite ideal hacia el cual converge el proceso abstractivo de conjuntos gradualmente menores de propiedades secundarias. Es el resultado ideal de esta convergencia. La geometría y otras habilidades del levantamiento de mapas ayudan a representar esta estructura ideal en una forma espacio-temporal. Se dice que estas representaciones de la estructura ideal tienen propiedades primarias (aun cuando estrictamente las propiedades primarias no son nunca propiedades sensibles y pertenecen sólo a la estructura ideal misma y no a su representación).

Las propiedades primarias y secundarias se unen por un cierto procedimiento que alinea las dos dimensiones de la cosa, la real y la ideal, la material y la formal, una junto a otra. Éste es el procedimiento de la medición. El mapa, en cuanto resultado de una medición, ayuda a su vez a medir la región en sus diferentes aspectos. Forma un marco de referencia en el cual pueden registrarse y relacionarse todos los desarrollos subsecuentes. La medición es el acoplamiento de las propiedades secundarias con las primarias. $\mathrm{Y}$ su procedimiento es aplicar un conjunto de propiedades primarias representadas en un patrón -metro, segundo, gramo, etc., por medidas de es. pacio, tiempo y peso- a la cosa real concreta, tomando en consideración sólo aquel aspecto de la cosa que se ajusta al patrón. Este aspecto es entonces esa parte de la cosa $-\mathrm{y}$ de su conjunto de propiedades secundariasque corresponde a sus propiedades primarias, es la imagen especular de las propiedades primarias dentro del conjunto de las propiedades secundarias. Esta imagen especular es llamada el esquema de la cosa. Es la estructura formal de la cosa dentro de la cosa misma.

Así, pues, la relación entre propiedades primarias y secundarias es la relación entre una cosa concreta y su estructura formal. La estructura formal se origina con la ayuda de algún sistema formal. En general, por lo que respecta a las cosas externas, el sistema en cuyos términos se formalizan las cosas es la matemática. Las matemáticas son el patrón de efectos.

d) Propiedades secundarias y terciarias. Una vez que ha quedado clara la relación entre las propiedades secundarias y primarias, a saber, que las propiedades primarias representan la estructura pura del conjunto de propiedades secundarias, queda libre el camino para entender la relación entre las propiedades secundarias y las terciarias. Y una vez que esta relación queda entendida, puede aclararse la relación específica entre hecho externo y valor extrínseco y hecho interno y valor intrínseco. 
Hemos dicho que las propiedades de valor son propiedades terciarias. Volvamos a nuestro agrimensor de la Región X. La recorre y la ve con una mirada muy cuidadosa y observadora. Advierte algo y toma notas de todo aquello que se ajuste a su propósito geométrico. Tanto el ingeniero minero, como el ecólogo y el general actúan igual, desde su punto de vista particular.

Pero imaginemos ahora que nosotros hacemos un viaje a través de la misma región. Es un bello día de verano, el paisaje está lleno de colorido, el aire es fragante, los pájaros gorjean en los árboles, los grillos cantan en la maleza, toda la naturaleza vive en torno nuestro y nosotros gozamos de ella con todos nuestros sentidos, la vivimos por todos nuestros poros. Hay una gran felicidad en nosotros. Nos sentimos serenos, enriquecidos, vivos.

Esta actitud es muy diferente de la del agrimensor, el ingeniero minero, el ecólogo o el general. Todos ellos vieron sólo aquello que deseaban ver, nosotros, en cambio, sólo deseamos entregarnos plenamente a la experiencia. Ellos sólo vieron partes de la región, recortando las secciones que convenían a su propósito. Nosotros no tenemos propósito alguno, lo vemos todo. Ellos analizaron la región con una mirada fría y calculadora; nosotros la absorbemos. Ellos estaban separados de ella, nosotros somos uno con ella. Nosotros estamos encantados, embelesados, ellos eran observadores fácticos. Las propiedades que nosotros vemos en el paisaje - su belleza, su fragancia, su encanto- son propiedades del todo diferentes de las propiedades secundarias del agrimensor o de las propiedades primarias del mapa. Son propiedades terciarias.

Volvámonos ahora del goce del paisaje hacia el análisis de nuestro gozo, de la valoración hacia el análisis de la valoración. Dejemos de ser valoradores y empecemos a ser axiólogos. Ahora bien, el problema es cómo podemos analizar y explicar las propiedades terciarias con la misma precisión con la que las propiedades secundarias son analizadas y explicadas por las propiedades primarias. ¿Cómo podemos levantar un mapa, por así decirlo, de la belleza, fragancia y encanto de este día veraniego?

Regresemos a nuestra fórmula:

Las propiedades secundarias son, respecto a las terciarias, lo que las propiedades primarias respecto a las secundarias.

Puesto que sabemos cuál es la relación entre las propiedades primarias y las secundarias, todo lo que tenemos que hacer es aplicar esta relación a la relación entre propiedades secundarias y terciarias. E1 resultado es el siguiente: las propiedades secundarias son la representación de la estructura ideal de las propiedades terciarias. Miden -valorativamente- las propiedades terciarias. Están dentro de las propiedades terciarias como un esquema o esqueleto. Lo que el agrimensor, el ingeniero minero y cualquier observa- 
dor fáctico ven es el esquema de la naturaleza del valor del paisaje. Así; resulta obvio que lo que el valorador ve es más que lo que ve el "fáctico": lo que este último ve está "incluido" en lo que ve el primero, del mismo modo infinito en el que el mapa está incluido en la medición del geómetra. Así como el mapa es el límite de la reducción fáctica, así el hecho es el límite de la reducción valorativa. El agrimensor tiene que seguir un complicado proceso a fin de ver las propiedades primarias de la region; tiene que desmenuzarla hasta llegar a sus puntos esenciales, "A-K", abstrayendo a partir de la Descripción, a través de la Exposición, hasta la Definición. Después tiene que usar la definición, los lugares de medición, como puntos de partida para un comienzo enteramente nuevo, el de la medición misma, que lleva a la formalización simbólica del mapa.

Todo esto tiene su contrapartida en la valoración. Las propiedades terciarias, o de valor, deben ser desmenuzadas mediante algún procedimiento análogo al de la abstracción o reducción, de la descripción a la definición. Debe surgir una definición, o definiciones del valor, aun en términos de propiedades terciarias, y de este resultado debe darse un salto hacia la formalización. Las propiedades terciarias son respecto al valor lo que las secundarias respecto al hecho, son las "propiedades secundarias" del valor. Y las propiedades secundarias del hecho son las propiedades primarias del valor. Así, el análisis de la valoración, o la formalización de la valoración, es el conjunto de las propiedades secundarias del hecho. Lo que el agrimensor y el ingeniero de minas ven aparece formalizado como propiedades "primarias" del valor. Las propiedades secundarias son la formalización de las propiedades terciarias. Esto presupone que las propiedades secundarias deben tener una cierta forma, de no ser así las propiedades de valor no podrían formalizarse en ellas; justo como las propiedades primarias - las geométricas y matemáticas - tienen una forma que hace posible que las propiedades secundarias sean formalizadas por ellas y a través de ellas. La forma del mundo del valor es la lógica de los predicados descriptivos.

Las propiedades primarias, secundarias y terciarias pertenecen a tres mundos diferentes y los determinan. El primero es el de los mapas, fórmulas, ideas, ideales, etc.; el segundo es el de los sentidos, el de la vida cotidiana, el Lebenswelt o mundo de la vida, según to ha llamado Husserl; el tercero es el mundo de los valores. El mundo cotidiano tiene una forma que explica el mundo de los valores. $Y$ el mundo de los ideales tiene una forma que explica el mundo cotidiano. Cada mundo explicativo es una reducción infinita, una disminución, un limite del mundo explicado: el mundo cotidiano tiene infinitamente menos propiedades que el mundo del valor; y el mundo ideal tiene infinitamente menos propiedades que el mundo cotidiano. Pero cada mundo "inferior" formaliza y organiza al superior. Y mientras más "inferior" sea el mundo, más alta será la organización. Mientras menos ele- 
mentos haya en un sistema, más apretada y coherentemente podrá organizarse éste.

Los tres mundos de cualidades primarias, secundarias y terciarias descritos hasta aquí constituyen los aspectos fundamentales del mundo en que hemos nacido. Desde luego, es posible ver el mundo desde una infinidad de otros aspectos; pero estos tres son los que importan al axiólogo y al análisis del valor.

e) La generalización axiológica. A fin de que esto sea del todo evidente, efectuaremos ahora una generalización final y decisiva, a la que puede darse el nombre de generalización axiológica. Diremos que los tres aspectos del mundo son todos ellos aspectos de valor y son todos los aspectos de valor que hay. Los llamaremos dimensiones de valor y llamaremos al mundo de propiedades primarias mundo de valor sistémico; al mundo de propiedades secundarias, mundo de valor extrinseco; y al mundo de propiedades terciarias, mundo de valor intrinseco. La división entre hecho y valor y su explicación respectiva desaparecen así de la vista del axiólogo. 'Todo lo que él considera son tres dimensiones del valor, sistémico, extrínseco e intrínseco; y su oficio consiste en distinguir estas tres dimensiones y la estructura de sus interrelaciones en cualquier situación posible. Damos a continuación unos cuantos ejemplos de dimensiones de valor en distintas situaciones:

Ejemplos de Dimensiones de Valor

\begin{tabular}{|c|c|c|c|}
\hline Situación & Dimensión Sistémica & Dimensión Extrinseca & Dimensión Intrinseca \\
\hline $\begin{array}{l}\text { Construcción de una } \\
\text { casa }\end{array}$ & Plano & $\begin{array}{l}\text { Inventario y descrip. } \\
\text { ción }\end{array}$ & "Hogar, dulce hogar" \\
\hline Un concierto & Partitura & $\begin{array}{l}\text { Orquesta e instrumen- } \\
\text { tos }\end{array}$ & Deleite musical \\
\hline $\begin{array}{l}\text { Confección de un pas- } \\
\text { tel }\end{array}$ & Receta & $\begin{array}{l}\text { Útiles de repostería, } \\
\text { masa y horno }\end{array}$ & Saboreo del pastel \\
\hline $\begin{array}{l}\text { Compra de un auto- } \\
\text { móvil }\end{array}$ & $\begin{array}{l}\text { La cuenta, la factura } \\
\text { las especificaciones }\end{array}$ & El automóvil & El placer de manejar \\
\hline Un matrimonio & El aspecto legal & $\begin{array}{l}\text { La despedida de solte- } \\
\text { ra, el banquete, la } \\
\text { dote }\end{array}$ & La luna de miel \\
\hline Nacimiento de un niño & E1 aspecto médico & $\begin{array}{l}\text { El "Baby shower", la } \\
\text { ropa, la cuna, el } \\
\text { cuarto }\end{array}$ & El niño \\
\hline
\end{tabular}

En este cuadro, las Dimensiones de Valor aparecen separadas en forma adecuada. En las situaciones reales están interrelacionadas de muchas maneras diferentes y forman estructuras complejas. Estas estructuras pueden ser Composiciones, en las que los valores se refuerzan mutuamente, o Transposiciones, en las que los valores se destruyen unos a otros. Pero ambas, la 
composición y la transposición, alcanzan de lo trivial a lo sublime. Así, es una transposición el manchar un vestido, pero lo es también el sacrificar un hijo, como en la historia bíblica de Abraham y en la clásica de Ifigenia, o el destruir una vida para mantener la ley, como sucede en El cónsul de Gian-Carlo Menotti y en la Antigona de Sófocles.

El axiólogo, en vez de ver el mundo desde el punto de vista del hecho, lo ve desde el punto de vista del valor. La noción de propiedades primarias, secundarias y terciarias le ayuda a superar la ruptura entre hecho y valor. En el terreno neutral de estas tres clases de propiedades, reinterpreta las propiedades primarias como valores sistémicos, las secundarias como valores extrínsecos y las terciarias como valores intrínsecos, y usa la relación entre las tres clases de propiedades a fin de explicar la que existe entre las tres clases de valores.

Hasta ahora, esta reinterpretación se ha hecho a partir del hecho externo. Las propiedades en cuestión son las del hecho externo: las propiedades primarias son las de la ciencia natural; las secundarias las de las cosas naturales y sucesos, o efectos, en el mundo natural; y las terciarias las de la experiencia, sin reservas, de tales efectos.

Pero ¿cómo proceder si las propiedades son las de los hechos internos o afectos? ¿Qué son entonces las propiedades primarias, secundarias y tercia. rias? Esta pregunta nos conduce a un nuevo terreno - y al corazón mismo de la valoración y de su análisis.

\section{Valoración y hecho interno (afecto)}

También los hechos internos pueden ser valorados sistémica, extrínseca e intrínsecamente. Pero la naturaleza misma de los hechos internos hace que la valoración de ellos sea diferente de la de los hechos externos. Hay dos diferencias principales.

La primera es que cualquier valoración de un hecho externo va acompañada de un hecho interno, pero que, viceversa, no todas las valoraciones de un hecho interno van acompañadas de un hecho externo. La segunda es que ambas, la valoración de un hecho externo y la de un hecho interno, son intensificaciones de ese hecho, pero la intensificación de un hecho externo es algo diferente a la de un hecho interno.

a) La valoración de un hecho externo va acompañada por un hecho interno. El niño que rueda las escaleras, la madre que le da unas nalgadas, el capitán que mira el oleaje, el físico que lo analiza, el agrimensor que observa una región, el sacerdote que casa a una pareja, la madre que carga al niño, todos éstos son valores y todos tienen ciertas cogniciones, percepciones, emo- 
ciones, experiencias que acompañan la valoración, pero que no son la valoración. Estas cogniciones, percepciones, emociones y experiencias son hechos internos. Cada una de las tres clases de valoración tiene su propio hecho interno acompañante. Así, la valoración sistémica o simbolización va acom. pañada por una actividad mental especifica que es parte de la cognición en general. La cognición, de uno y otro tipo, acompaña toda valoración sistémica. Sin embargo, la cognición no es la valoración sistémica. La valoración sistémica es imbuir la cosa, asi valorada, con propiedades primarias. Dado que las propiedades primarias son propiedades simbólicas y los símbolos no pueden ser reconocidos sin la cognición, ésta es una condición necesaria de la valoración sistémica. Es un medio para llegar a esa valoración. Es el hecho interno particular que acompaña a la valoración sistémica.

La percepción es el hecho interno que acompaña la valoración extrínseca. La valoración extrinseca es imbuir la cosa, asi valorada, con propiedades secundarias. Éstas son propiedades sensibles - las que aprehendemos al ver, oír, gustar, oler, tocar, etc. No podemos hacerlo sin la percepción. La percepción, en el sentido más amplio, es una condición necesaria para la valoración extrínseca. Es el hecho interno particular que acompaña este tipo de valoración.

El hecho interno que acompaña la valoración intrínseca es más difícil de determinar. La psyche humana al efectuar una valoración sistémica añade sus facultades mentales a la cosa valorada y la aprehende en términos de estas facultades: como una cosa simbólica. En la valoración extrínseca la psyche humana añade sus facultades sensibles a la cosa valorada y la aprehende en términos de estas facultades: como una cosa observada y como parte de una clase de cosas observadas similares. Pero en la valoración intrínseca la psyche humana no añade ninguna facultad particular a la cosa valorada - simplemente se añade toda ella a la cosa, se entrega a ella "sin reservas". Esta entrega sin reservas es el hecho interno que acompaña la valoración intrínseca. Lo llamamos experiencia. La experiencia, de acuerdo con el Webster's New Collegiate Dictionary, es "el vivir realmente un suceso o sucesos; un goce o sufrimiento real; de aquí el efecto sobre el juicio o los sentimientos, producido por las impresiones personales y directas; ...la suma total de los sucesos conscientes que componen una vida individual", o cualquiera de estos sucesos. En otras palabras, la experiencia es mi ser total en un cierto momento, es un corte seccional de mí mismo en mi plenitud en una ocasión determinada. Es, como dicen los alemanes, un Eriebnis, "un vivir a través de algo" o, como se dice en español, una vivencia, una experiencia vivida." Por ser tal corte seccional de cualquier momento de toda mi vida interna,

- "Vivencia: Hecho de experiencia que, con participación consciente o inconsciente del sujeto, se incorpora a su personalidad." Diccionario de la Lengua Española, Real Academia Española, 1956. 
contiene en una mezcla compleja todos los hechos internos; la cognición y la percepción, la emoción y el conato, sumando entre todos ese sentimiento particular de excitación, sentimiento aumentado de vida, que es característico de una gran experiencia, ya sea de goce o de sufrimiento.

Así, pues, la experiencia en este amplio sentido es el hecho interno que acompaña la valoración intrínseca. No puedo valorar algo intrínsecamente a menos que experimente, profunda y plenamente, lo que valoro. Pero la experiencia no es la valoración intrínseca. La valoración intrinseca es imbuir la cosa, asi valorada, con propiedades terciarias.

Por lo tanto, los tres hechos fundamentales internos que acompañan, respectivamente, la valoración sistémica, la extrínseca y la intrínseca son la Cognición, la Percepción y la Experiencia. Así, pues, la valoración de un hecho interno significa la valoración de la Cognición, la Percepción y la Experiencia. Dado que estos hechos internos acompañan la valoración de los hechos externos, su valoración, a su vez, añade una nueva dimensión a la valoración de los hechos externos. Pues la valoración de éstos puede ir acompañada no solamente por estos hechos internos, sino también por la valoración de estos hechos.

La valoración de los hechos internos no puede diferir, por naturaleza, de la de los hechos externos. La valoración es siempre valoración. De ahí que, si la valoración de los hechos externos va acompañada por ciertos hechos internos, la valoración de los hechos internos debe ir acompañada por esos mismos hechos internos. La valoración sistémica va acompañada por la cognición, sea lo que se valore un hecho externo o interno; la valoración extrínseca va acompañada por la percepción, sea que se trate de la valoración de un hecho externo o de uno interno; y la valoración intrínseca va acompañada por la experiencia, sea que el objeto de la valoración sea un hecho externo o uno interno. De ahí que, si la Cognición, la Percepción y la Experiencia han de ser valoradas sistémica, extrínseca e intrínsecamente, estas valoraciones deben ir acompañadas respectivamente por la Cognición, la Percepción y la Experiencia. Así, pues, la valoración del hecho interno de la Cognición, en las tres dimensiones, va acompañada por la cognición, la percepción y la experiencia respectivamente; es decir, la cognición valorada aparece en términos de cognición, percepción y experiencia respectivamente. De modo semejante, la percepción valorada aparece en términos de cognición, percepción y experiencia respectivamente; y así lo hace también la experiencia valorada.

Esto significa que no sólo la valoración del hecho externo va acompañada de un hecho interno, sino que cualquier valoración, sea de un hecho externo o interno, lo va también.

De acuerdo con los términos de un cuadro, estas relaciones aparecen en la forma siguiente: 
Valoración de hechos internos

\begin{tabular}{|c|c|c|}
\hline Hecho Interno & Valorado & Acompañado par \\
\hline Concepción & Sistémicamente & Concepción \\
\hline Extrínsecamente & Percepción \\
\hline Intrínsecamente & Experiencia \\
\hline Sercepción & Sistémicamente & Concepción \\
\hline Experiencia & Intrínsecamente & Percepción \\
\hline Sistémicamente & Experiencia \\
\hline Extrínsecamente & Concepción \\
\hline Intrínsecamente & Percepción \\
\hline
\end{tabular}

Así, pues, la valoración de los hechos internos se vuelve, por así decirlo, hacia sí misma. Los hechos internos se refuerzan unos a otros en la valoración (o se oponen unos a otros en la desvaloración). Hay así una relación mucho más estrecha entre el hecho interno y la valoración que entre el hecho externo y la valoración. Esto nos conduce a la segunda diferencia mencionada entre las dos clases de valoración.

b) La intensificación de un hecho externo es diferente de la intensificación de un hecho interno. Supongamos que una cosa es valorada progresivamente, primero sistémica, luego extrínseca y, por último, intrínsecamente. Por ejemplo, una persona ve primero un mapa de Río de Janeiro y lee todo lo que puede acerca de la ciudad, hasta que llega a conocer todo lo que le es posible -esto es la valoración sistémica: la ciudad es un conjunto de pensamientos e imágenes en su mente; después, visita Río y camina por sus calles, mira sus tiendas, llega a conocer su largo y su ancho y en especial sus alturas y logra encontrar hábilmente su camino por ella- esto es la valoración extrínseca: Río es percibida y observada como una ciudad particular; y una noche de luna, mirando la ciudad desde la altura del Corcovado, con la estatua de Cristo tras él, a sus pies el agua plateada de la bahía, el centelleo increíble de millones de luces, y ante él las oscuras siluetas de las rocas, se enamora de Río de Janeiro - - esto es la valoración intrinseca: Río es una experiencia única e irrepetible. $O$, por variar el ejemplo, supongamos que un joven ve el retrato de una muchacha, como Tamino en La flauta mágica; después le presentan a la muchacha y llega a hacer amistad con ella; por 
último se enamora de ella. En todos estos casos, la cosa en cuestión se ve primero bajo la forma de propiedades primarias (en el caso de la muchacha una radiografía de ella sería más definidamente sistémica, como la radiografía de Madame Chauchat que Hans Castorp admira en La montaña mágica de Thomas Mann), después de propiedades secundarias y luego de propiedades terciarias. Así como las propiedades secundarias eran reducciones de las terciarias, y las propiedades primarias reducción de las secundarias, así, a la inversa, las propiedades secundarias son un enriquecimiento de las primarias y las terciarias un enriquecimiento de las secundarias. Este proceso de enriquecimiento es lo que llamamos un proceso de intensificación. La cosa es aprehendida progresivamente con mayor intensidad.

En el caso del hecho externo, esto significa que la cosa se va haciendo más y más personal, en realidad se va haciendo más y más interna; porque en el amor apenas existe diferencia entre el yo y el tú; y lo amado se convierte a tal grado en parte de mí mismo que la vida me parece inconcebible sin ello. Si me enamoro de Río de Janeiro haré todo lo posible por vivir allf y si me enamoro de la muchacha no descansaré hasta que su vida sea parte de la mía. Así, la intensificación de un hecho externo por la valoración progresiva hace de este hecho un hecho más y más interno. Cambia, de modo fundamental, el carácter del hecho. El hecho externo, en cuanto símbolo, está apartado de mí y yo estoy alejado de él, lo manejo indiferentemente; el hecho externo, en cuanto percibido, está mucho más cerca de mí, mis sentidos juegan sobre él, lo veo, lo toco, lo oigo, lo huelo, lo gusto; y a fin de ser aprehendida en esta forma la cosa debe estar lo bastante cerca para ser accesible a mis sentidos. En tanto que, para ser aprehendida en forma simbólica, la cosa puede estar en cualquier lugar, aunque no sea la Tierra. Y la cosa experimentada debe estar tan cerca de mí que sea parte de mí mismo, y yo tan cerca de ella que sea parte suya. ${ }^{7}$

La valoraçión de una cosa interna es, por naturaleza, distinta de la valoración de una cosa externa. De ahí que, así como la intensificación progresiva de valorar una cosa externa la hace progresivamente interna, así la intensificación progresiva de valorar una cosa interna debe hacerla progresivamente más interna. $\mathrm{Y}$ es evidente que el convertirse en algo interno no significa un cambio fundamental de la naturaleza de la cosa interna, como lo es en la naturaleza de la cosa externa. Por el contrario, significa afirmar cada vez más esa naturaleza. En la intensificación progresiva, la cosa interna se convierte cada vez más en lo que es y la cosa externa se convierte cada vez menos en lo que es -o cada vez más en lo que no es. De ahí la famosa noción de la "irrealidad" de los valores. Tiene validez solamente para cosas externas. Para las internas, el valor es realidad aumentada.

7 Ortega y Gasset da a esto el nombre de "distancia espiritual" entre nosotros y las situaciones. La deshumanización del arte, Obras completas, III, pág. $3^{61 .}$ 
El proceso de convertirse cada vez más en lo que la cosa es se llama proceso de diferenciación; la cosa se diferencia cada vez más dentro de sí misma. Es un proceso de crecimiento interno; como lo es, por ejemplo, todo proceso orgánico. La valoración de un hecho interno, procediendo como lo hace dentro del hecho interno mismo, es un proceso de diferenciación, un proceso dinámico similar al del crecimiento orgánico. Es el crecimiento de la propia vida interna. La valoración progresiva de un hecho interno es nuestro crecimiento hasta alcanzar la plenitud de nuestro ser. Es nuestra propia autointensificación. Pues la totalidad de todos los hechos internos es nuestro propio yo. $\mathrm{Y}$ cada hecho interno es un fragmento de nuestro yo. ${ }^{8}$

Así, pues, el proceso de valoración progresiva de un suceso interno significa la diferenciación progresiva de ese suceso. La Cognición progresivamente valorada se convierte cada vez más en una cognición diferenciada; la Percepción progresivamente valorada se convierte en una percepción cada vez más diferenciada; y la Experiencia progresivamente valorada se convierte en una experiencia cada vez más diferenciada.

Si bien existe una diferencia entre los tres aspectos de valor de una cosa externa, no existe tal diferencia entre los tres aspectos de valor de una cosa interna. El mapa de Río es algo totalmente diferente de la ciudad misma, y Río de Janeiro como una experiencia total es, a su vez, algo totalmente diferente de la ciudad vista desde un autobús. Pero una cognición conocida, percibida y experimentada es una cognición cada vez más profunda.

Ahora se nos plantea el problema de a dónde conduce la intensificación de un hecho interno. Por ejemplo, ėa dónde conduce la diferenciación cada vez más intensa de la Cognición? Debe conducir a una interiorización cada vez más profunda. En verdad, como veremos más adelante, las tres formas del hecho interno se siguen una a otra como etapas de intensificación. Así, pues, no están separadas sino que forman un espectro que, en su totalidad, es justo el hecho interno o afecto. La Cognición intrínsecamente experimentada se convierte en Percepción, y la Percepción intrínsecamente experimentada se convierte en Experiencia. Así, veremos que la regla válida para los hechos externos es también válida para los internos: que las propiedades primarias de los hechos internos son, respecto a las propiedades secundarias de estos mismos hechos, lo que las propiedades secundarias de los hechos inter. nos son con respecto a sus propiedades terciarias.

A fin de entender esto, examinaremos ahora la naturaleza del hecho interno y de su valoración.

c) ¿Qué son los hechos internos? Un hecho interno es cualquier cosa que sucede dentro de nosotros: un pensamiento, una visión, un sentimiento, una

8 Por otra parte, la interiorización de una cosa externa puede ser lo que Freud (y ya antes Kant) llamó Besetzung, kathexis. 
experiencia. Es evidente que todo esto puede ser valorado. Así, puedo gozar de un cierto pensamiento, una cierta visión, un cierto sentimiento o una cierta experiencia. Y este goce debe ser algo diferente ya sea del pensamiento, la visión, el sentimiento o la experiencia. No sólo puedo gozar de estos hechos internos, es decir, valorarlos intrínsecamente, sino valorarlos, como hemos visto, en las tres dimensiones de valor: simbolizarlos, medirlos, clasificarlos, observarlos y amarlos; y por turno, conocerlos, percibirlos y experimentarlos. Puedo realizar todas estas operaciones con los hechos internos dentro de mi y, por ello, la valoración de estos hechos ocurre por completo dentro de mí; sin embargo, consta de tres partes que deben ser claramente distinguidas: el hecho interno, su valoración y el hecho interno acompañante. La razón por la que resulta tan difícil mantenerlas separadas es que la valoración de un hecho interno es una operación que, por una parte, va acompañada por un hecho interno y, por la otra, se aplica $a$ un hecho interno, convirtiéndolo en un valor; y todo esto sucede dentro de nosotros. De ahí que las confusiones entre valoración y sentimiento, señaladas más arriba, nada tengan de sorprendentes. Aparecen de modo más notable en la confusión entre sexualidad y amor, por ejemplo. Los pensamientos, las visiones y los sentimientos de la sexualidad son hechos internos; el amor es la valoración de un hecho interno: el carácter de otra persona. Si esta persona es del sexo opuesto, va acompañado por la sexualidad; pero no es la sexualidad. En general, si identificáramos un sentimiento con su valoración intrínseca, nunca llegaríamos a saber si lo que tenemos es el valor de un sentimiento, el sentimiento de un valor, el valor de un valor o el sentimiento de un sentimiento.

Como hemos visto, el hecho interno cae bajo las tres categorías de la concepción o pensamiento, la percepción o sensibilidad, y la experiencia. Elegimos estas tres como nuestros hechos internos fundamentales porque son las que acompañan, respectivamente, a las tres dimensiones de valor. Existen otros hechos internos, en especial la emoción y el conato (volición, deseo) que acompañan otras dimensiones del valor (la transposicional y la teleológica, respectivamente).

Concepción. La concepción es la función de la mente. Consiste de dos subdivisiones, la concepción pura y la aplicada. La concepción pura es un asunto de la imaginación y o bien no tiene referencia alguna con el mundo exterior o bien sólo la tiene indirecta. Puede ser sistemática (formal) o asistemática (material). En la primera, la imaginación se pone reglas exactas, como en la lógica, las matemáticas, la geometría, la topología, la teoría musical, la axiologia misma, etc., todas las cuales son tipos de imaginación muy formalizados que no tienen relación alguna con el mundo exterior. En la segunda, la imaginación no se pone ninguna regla sino que juguetea, por așí decirlo, consigo misma, como en los sueños, las ensoñaciones, la fantasía, 
etcétera. Esta clase de imaginación se refiere en forma inmediata al mundo material; es la imaginación material. La concepción aplicada (pensamiento) se refiere al mundo espacio-temporal: al pasado en la Memoria, al presente en la Apercepción (Cognición, Reconocimiento) y al futuro en la Anticipación.

Percepción. La percepción es la función de los sentidos - vista, oído, olfato, gusto, tacto- y consta de las actividades físicas y mentales conectadas con los sentidos y los órganos sensoriales. Los sentidos no se limitan a cinco, existen animales y aun personas que tienen seis o más sentidos y son receptivos a la gravitación, como los pájaros migratorios, o a los ultrasonidos, como los murciélagos.

Experiencia. La experiencia es la función del 'Yo. Consta del tener conciencia, del estar presente en la totalidad del propio ser. Es presencia total, entrega completa de uno mismo, en una cierta situación o en una cierta ocasión, a algo interno o externo.

Es evidente que estos hechos internos tienen una gran complejidad y que el tratar plenamente su valoración presupondría un examen detallado de cada uno de ellos. Sería tanto como hacer una psicología axiológica. Para los propósitos de este ensayo basta con el presente examen de los hechos internos. Estos hechos, en forma tabular, son los siguientes:

Los hechos internos

\begin{tabular}{|c|c|c|}
\hline \multirow{5}{*}{$\begin{array}{l}\text { Concepción } \\
\text { (Mente) }\end{array}$} & \multirow{2}{*}{$\underset{\text { (Imaginación) }}{\text { Pura }}$} & Sistemática (formal) \\
\hline & & Asistemática (material) \\
\hline & \multirow{3}{*}{$\begin{array}{c}\text { Aplicada } \\
\text { (Pensamiento) }\end{array}$} & Memoria (Pasado) \\
\hline & & Apercepción (Presente) \\
\hline & & Anticipación (Futuro) \\
\hline \multirow{6}{*}{$\begin{array}{l}\text { Percepción } \\
\text { (Sentidos) }\end{array}$} & & Vista \\
\hline & & Oído \\
\hline & & Olfato \\
\hline & & Gusto \\
\hline & & :Tacto \\
\hline & & Etc. \\
\hline $\begin{array}{l}\text { Experiencia } \\
\text { (Yo) }\end{array}$ & & Conciencia \\
\hline
\end{tabular}

3. La valoración de los hechos internos

La psicología axiológica sería la aplicación de las tres dimensiones del valor a cada uno de. estos hechos internos. A fin de proporcionar una ilus- 
tración, las aplicaremos al primero de ellos: la concepción pura sistemática, o sea, la imaginación formal.

La valoración de la concepción pura sistemática. Aquí, como ya hemos dicho, la imaginación se da sus propias reglas y procede de acuerdo con ellas en un sistema formal. Tomemos el pensamiento de que dos veces dos es igual a cuatro. Valoraremos este pensamiento sistémica, extrínseca e intrínsecamente. Después generalizaremos este último tipo de valoración.

Valoración sistémica significa simbolización. De ahí que la valoración sistémica del pensamiento en cuestión signifique presentarnos los símbolos en cuestión " $2 \times 2=4$ " y su significado, que se nos da por el sistema de las matemáticas. Así, si $2 \times 2=4$, la raíz cuadrada de cuatro es dos; y debido a la definición de la multiplicación puede ser más dos o menos dos, $\vee_{4}= \pm 2$. Así, la valoración sistémica del pensamiento en cuestión nos conduce al sistema de las matemáticas y es de hecho pensamiento matemático. Me fuerza no sólo a pensar los símbolos en cuestión, sino los de la multiplicación en general, de la evolución (extracción de raíces) en general, de los números positivos y negativos, en resumen todo el sistema del cual estos símbolos son una parte. El hacer matemáticas es, pues, la valoración sistémica de un hecho interno. ${ }^{9}$ El hecho interno en cuestión es una concepción pura sistemática. A ella se aplica todo un sistema de tales concepciones. Estas últimas no son la valoración, pero la acompañan. Son los medios por los cuales se realiza la valoración. En la valoración sistémica de una concepción pura sistemática, es decir, su simbolización, hay, en consecuencia, dos niveles de cognición, la cognición que está siendo valorada y la cognición por medio de la cual se lleva a cabo la valoración. Pero ni la una ni la otra es la valoración en cuestión.

Pasaremos ahora a la valoración extrinseca del pensamiento de que dos veces dos es igual a cuatro. Esto significa que el pensamiento ha de ser aplicado a una situación en el mundo cotidiano de espacio y tiempo. Tal es el caso, por ejemplo, cuando tengo dos cosas, $v$. gr., me he mandado a hacer dos trajes y quiero duplicar la orden. Entonces el hecho interno de que dos veces dos es igual a cuatro, aplicado a esta situación, me dice que, después de duplicar la orden, tendré cuatro trajes. Cualquier aplicación de las matemáticas es una valoración extrínseca del pensamiento matemático en cuestión. Lo que es, desde luego, muy importante en los negocios. Por ejemplo, la contabilidad no es más que la aplicación del pensamiento matemático a ciertas actividades en el mundo espacio-temporal. En el trabajo de actuario, el cálculo teórico de las estadísticas es valorado extrínsecamente al ser aplicado a ciertos sucesos del mundo. En general, la aplicación de un sistema cualquiera a cualquier suceso es la valoración extrínseca del sistema en cues-

๑ Esto, a su vez, es la definición axiológica del a priori, en todos sus sentidos. 
tión. Así, pues, toda la ciencia aplicada es la valoración extrínseca de un hecho interno.

Este tipo de valoración tiene dos filos. Al ser aplicado el sistema al mundo, tal sistema es valorado extrínsecamente. Pero, al mismo tiempo, el mundo es valorado sistémicamente. El actuario ve los sucesos espacio-temporales, nacimientos y muertes, personas enfermas y sanas, vehículos en uso y accidentes, de un modo sistémico, como datos para el cálculo estadístico. El contador no ve el sudor y la habilidad de los obreros y supervisores de la fábrica, sino los números y curvas que producen en sus tablas y gráficas. Así, la valoración extrínseca de un hecho interno sistemático significa, a la vez, la valoración sistémica de un hecho externo.

Sin la Percepción es imposible aplicar el pensamiento puro sistemático de que dos veces dos es igual a cuatro al mundo espacio-temporal, es decir, la valoración extrínseca de este pensamiento. Tengo que ver las cosas antes de aplicarles la multiplicación, tengo que observar los sucesos a fin de aplicar el cálculo estadístico, tengo que inspeccionar la fábrica y su producción antes de poner tal producción en números. Pero la percepción no es la valoración extrinseca. Es el hecho interno que acompaña tal valoración.

Volvamos ahora a la valoración intrínseca del pensamiento de que dos veces dos es igual a cuatro. Esto significaría entregarnos $\sin$ reservas $y$ sin prejuicios al pensamiento de que dos veces dos es igual a cuatro. Tendríamos que vivir este pensamiento con todo nuestro ser. Lo que resulta un poco extraño. ¿Qué hay en dos veces dos es igual a cuatro que sea tan interesante que se deseara vivir ese pensamiento? Sin embargo, hubo una época en que había enigmas fascinantes contenidos en esta multiplicación y en la involución y evolución, elevación de números a potencias más altas y extracción de las raíces, en general. En particular, la raíz cuadrada de dos dio origen a interminables enigmas. El gozo de Pitágoras al descubrir su teorema -que la suma de los cuadrados de los catetos es igual al cuadrado de la hipotenusa- fue tan enorme que sacrificó una hecatombe al dios Apolo, quien le había revelado personalmente esta profunda verdad del pensamiento divino. Pero su gozo se convirtió en tristeza sin límites cuando descubrió que el cuadrado sobre la diagonal de un cuadrado con lados de una medida de unidad sería $1+1=2 \mathrm{y}$, por ello, la diagonal misma la raíz cuadrada de dos. Esta raíz cuadrada no era un número en el sentido pitagórico, ni integral ni fracción, era una irracionalidad y, hasta hoy, se le llama un número irracional. Para nosotros esto sólo significa que sus decimales no siguen una ley periódica, como los de las fracciones (por ejemplo, $\frac{1}{7}=0.142857142857$ etc.). Para Pitágoras, que creía que Dios mismo y todo lo que contiene el mundo era un número, significó literalmente que el mundo se derrumbó bajo sus pies y el cielo sobre su cabeza - que su vida y la vida misma carecían de sentido. Había 
valorado el número intrínsecamente y ahora tenía que desvalorar intrínsecamente esta valoración intrínseca. El resultado fue, según algunas fuentes, que hizo asesinar a algunos de sus hermanos de la fraternidad pitagórica que dudaban de su sabiduría.

Por extraño que parezca, la historia está llena de ejemplos de exaltación y desesperación humanas, de amor y discordia, de felicidad y tortura, a causa de la valoración intrínseca del pensamiento sistemático o de pensamiento considerado como tal. Otro adorador del número, Galileo, casi llegó a ser torturado porque su concepción del papel cósmico del número estaba en conflicto con la de la autoridad medieval. Calvino hizo quemar a Servet a fuego lento por algunas diferencias de dogma. $Y$ en la actualidad el mundo se ve amenazado con la extinción total a causa de la valoración intrínseca de otro trozo de imaginación pseudosistemática, la noción de sistemas económicos. Muchas, si no todas, de las grandes catástrofes colectivas de la humanidad pueden rastrearse hasta la valoración intrínseca de alguna concepción sistemática combinada con la desvaloración intrínseca de otra concepción semejante. Cuando la valoración intrínseca de tal concepción no va acompañada de la desvaloración intrínseca de otra concepción semejante, el resultado pueden ser concepciones profundas y fructíferas. En verdad, pertenece a la naturaleza de toda concepción verdaderamente sistemática -una concepción que sea sistemática en el sentido formal, tal como es definido por los lógicos, y no pseudosistemática en el sentido material, como lo son los "sistemas" dialécticos y dogmáticos_ el ser universalmente válida y no necesitar del empujón humano para ser aceptada entre los hombres. Los hombres la aceptan voluntariamente y no hay que forzarlos a hacerlo. Los sistemas que han de forzarse a ser aceptados por la gente son siempre pseudosistemas. Las concepciones verdaderamente sistemáticas no necesitan un empujón, ya que tales verdades son innatas en la propia mente racional del hombre. No se necesita propaganda alguna para difundir la nueva de que $2 \times 2=4$. Todo lo que estas verdades necesitan es alguien que las anuncie. Las verdades de este tipo no son sólo las verdades matemáticas, sino también las verdades lógicas, musicales, ${ }^{10}$ axiológicas y ciertas verdades puramente formales ontológicas y teológicas. ${ }^{11}$ Los matemáticos han entregado sus vidas a la valoración intrínseca de concepciones sistemáticas y han compartido los gozos y tristezas de Pitágoras. Han producido fórmulas que han dirigido la vida humana durante siglos, por ejemplo, las leyes del movimiento planetario de Kepler, la ley de la gravitación de Newton y, en nuestros días, la teoría de la relativi-

10 Véase Alain Gheerbrant. Journev to the Amazon, Nueva York, 1954, con respecto a la aceptación de Mozart por los aborígenes del Amazonas.

11 Como la prueba de San Anselmo de la existencia de Dios. Véase Karl Barth, Fides Quaerens Intellectum, Darmstadt, 1958; Charles Hartshorne, Anselm's Discovery, Lasalle, Ill., 1965; y Robert S. Hartman, "Prolegomena to a Meta-Anselmian Axiomatic", Review of Metaphysics, xıv, No 4 (junio 1961), págs. 637-675. 
dad de Einstein, que está configurando la edad atómica. Ninguna de ellas necesita propaganda. Se expanden por sí solas y la técnica moderna es su monumento. Los místicos han valorado intrínsecamente algunas nociones de Dios, y sus visiones - frente a los dogmas y credos de las institucioneshan atraído a los hombres y mujeres de sensibilidad igual. Todos los místicos en todas las culturas de todos los tiempos han tenido, esencialmente, la misma visión. Todas ellas son valoraciones intrínsecas de concepciones sistemáticas puramente formales.

Estas valoraciones van acompañadas por la excitación de espíritu que es característica de lo que llamamos Experiencia. Daremos dos ejemplos tomados de las matemáticas y uno tomado de la teología para ilustrar la valoración intrínseca de concepciones puramente sistemáticas y la excitación que la acompaña. ${ }^{12}$

El primero está tomado de las obras de Johannes Kepler ${ }^{13}$ y se refiere a su descubrimiento de la tercera ley del movimiento planetario: que el cuadrado de los periodos de revolución de dos planetas cualesquiera alrededor del sol es igual al cubo de sus distancias respecto al sol.

Lo que se me ocurrió, veinticinco años antes de haber descubierto los cinco cuerpos regulares entre las órbitas celestes...; lo que proclamé hace dieciséis años como el fin último de toda investigación; lo que me llevó a consagrar los mejores años de mi vida a los estudios astronómicos, a unirme a Tycho Brahe y a fijar mi residencia en Praga - lo he logrado, con la ayuda de Dios, que puso fuego a mi entusiasmo y me despertó un deseo irreprimible, que mantuvo mi vida y conservó alerta mi inteligencia y también provió mis necesidades restantes por medio de la generosidad de dos Emperadores y de los Estados de mi patria, la Alta Austria - lo he logrado sacar ahora finalmente a luz, después de desempeñar mis deberes astronómicos ad satietatem... Percibí los primeros resplandores de la aurora hace dieciocho meses, la luz del día hace tres meses y sólo hace unos cuantos días el pleno sol de la más maravillosa visión -ahora nada me detendrá. Sí, me entrego a la divina locura. Desafío burlonamente a todos los mortales con esta confesión abierta: he robado los vasos de oro de los egipcios para hacer con ellos un tabernáculo para mi Dios, lejos de las fronteras de Egipto. Si me perdonáis, me alegraré. Si os enojáis, lo soportaré. Mirad, he lanzado los dados y escribo un libro ya sea para mis contemporáneos o para la posteridad. Me da igual. Si he de esperar cien años para encontrar un lector, Dios ha esperado seis mil para encontrar un testigo...

12 El ejemplo de Arquímedes es demasiado bien conocido para ser mencionado.

13 Harmonice Mundi, 1619 , Introducción al libro $V$. 
El segundo está tomado de uno de los textos más famosos del pensamiento teológico occidental, el Prefacio de San Anselmo a su prueba de la existencia de Dios en el Proslogion. Durante años, Anselmo había luchado por encontrar una concepción sistemática pura de Dios, independiente de toda autoridad de la Iglesia o del dogma, basada sólo en el puro pensamiento racional y de la cual pudieran deducirse todos los atributos de Dios. "Entonces empecé a investigar si acaso no podría hallarse un argumento que no necesitase de ningún otro para probarse a sí mismo, y que se bastase para asentar que Dios existe verdaderamente... Dirigiendo mi pensamiento con frecuencia y celo hacia ese punto, creía a veces poder alcanzar lo que estaba buscando, y otras veces el mismo objeto escapaba por completo a la penetración de mi espíritu; por fin, desesperado, quise desistir de esa investigación, como si versara sobre algo imposible de hallar. Tenía la firme voluntad de desterrar totalmente de mi espíritu ese pensamiento, para que no lo distrajese, por una ocupación inútil, de otros en que me era posible progresar; pero entonces, y cada vez más, empezó a invadirme con una especie de impunidad. Así fue como un día, cansado de haberme resistido con violencia a ese importuno pensamiento, aquello que habia desesperado de encontrar se ofreció a mí en el mismo conflicto de ideas; por lo cual estudiosamente abracé el pensamiento que, en mis inquietudes, desechaba."

El concepto encontrado por Anselmo fue una definición sistemática pura de Dios: el ser mayor del cual ninguno puede pensarse. De la descripción de su biógrafo Eadmero podrá verse cómo valoró esta definición.

Entonces volvió su pensamiento hacia la cuestión de si podría probarse, por un único y breve argumento, lo que el credo y el sermón afirman de Dios: que existe desde la eternidad, inmutable, todopoderoso, omnipresente... y cómo todos estos atributos podían ser uno solo en Él (Juan, XviI, 21). Esto, como lo ha dicho él mismo, le ocasionó grandes dificultades. Pues este pensamiento no lo dejaba dormir, comer ni beber. Y, lo que le causaba la mayor preocupación, perturbaba sus devociones, tanto en maitines como en las otras. Cuando se percató de esto, sin que le fuera aún posible alcanzar lo que buscaba, creyó que tales pensamientos eran quizá tentaciones del demonio y trató con todas sus fuerzas de desterrarlas de su espíritu. Pero mientras más empeño ponía en ello, más le asaltaban. Y una noche, durante maitines, sucedió que la gracia divina iluminó su corazón y vio ante sí el objeto de su búsqueda. Y todo su ser se llenó de un gozo y un júbilo indescriptibles. ${ }^{14}$

14 Eadmeri monachi Cantuariensis Vita Sancti Anselmi archiepiscopi Cantuariensis, ed. R. W. Southern, Thomas Nelson and Sons, Ltd., Edinburgo, 1962, págs. 29-3o. Cf. Bertrand Russell: "Recuerdo el momento preciso, un día de 1894 , mientras caminaba por Trinity Lane, cuando en un relámpago vi (o creí ver) que el argumento ontológico es válido. Había 
La valoración intrínseca del pensamiento sistemático puro no sólo trae consigo la excitación espiritual, sino que también hace que este pensamiento sea tan claro que parezca apresable físicamente. Los ojos de la mente ven el pensamiento como una forma concreta o Gestalt: se convierte en una percepción mental. Es decir, el pensamiento sistemático puro, valorado intrínsecamente, se convierte en percepción, un tipo de percepción que no necesita de los sentidos. La llamaremos Intuición Sistemática. Es la experiencia de la concepción sistemática. ${ }^{15}$

La percepción sensible es sólo un tipo especial de percepción, el que se refiere al mundo espacio-temporal. Y, como se verá más adelante, la percepción sensible, en su más alta culminación, es decir, valorada intrínsecamente, trasciende los sentidos y se refiere a una realidad por completo diferente al mundo espacio-temporal. Así, pues, la percepción sensible es sólo una forma en el espectro de los hechos internos, a decir verdad, es en sí misma un espectro de tipos de percepción, entre la valoración intrínseca de la imaginación sistemática ( $\mathrm{y}$, como se verá, asistemática) y la valoración intrínseca de la percepción sensible misma.

Estos tres tipos de percepción se refieren a tres clases de cosas. La primera, la intuición, se refiere a cosas que la mente ve claramente y que están interrelacionadas con otras cosas iguales. Las cosas de este tipo se han llamado, tradicionalmente, Esencias. Así, pues, una esencia es el objeto de una intuición sistemática. La tercera ley de Kepler y la definición de Dios de San Anselmo son esencias en este sentido. Un cierto tipo de esencias se llama Axiomas (literalmente, "lo que vale la pena pensar"). Un axioma es una esencia que da origen a un sistema formal. Es (formalmente) una esencia creadora. La ley de la gravitación de Newton es una esencia de este tipo y, quizá, lo sea también la definición de Dios de Anselmo, si bien nadie ha deducido todavía el sistema implícito en ella.

Se dice que las esencias son "vistas" por el "ojo interior", por analogía con la percepción sensible. En realidad, son formas que la mente aprehende de modo directo, sin la intervención de los sentidos. Parecen ser vistas u oídas (como en el caso de las "voces" de los místicos), pero esto se debe tan sólo a que nuestro lenguaje, creado por la experiencia sensible y modelado de acuerdo con ella, no tiene otras palabras para comunicar esta experiencia. De hecho, cualquier persona de capacidad creadora ha tenido este tipo de experiencia. Los psicólogos de la Gestalt la llaman la experiencia "Ajá". Su característica principal, en el campo del pensamiento sistemático puro, es la concreción del objeto puramente imaginado, su aspecto de forma.

salido a comprar una lata de tabaco; a mi regreso, la arrojé de súbito al aire $\mathrm{y}$, al recoger1a, exclamé: 'Válgame Dios, el argumento ontológico es firme'." ("My Mental Development" The Philosophy of Bertrand Russell, Paul A. Schilpp, ed., Evanston, 1944, pág. 10.)

15 Compárese la Hyle noeté de Aristóteles, el eidos de Husserl y la acquaintance de Bertrand Russell. 
Abundan los ejemplos de "visiones" o "iluminaciones", desde luego, en la literatura religiosa. En muchos casos, es la lectura de un texto la que orjgina estas visiones que súbitamente aclaran el objeto de la búsqueda interna. Así, San Agustín encontró la claridad interior que lo había eludido por tantos años al leer la Epístola a los Romanos xiI, 19, y Santa Teresa al leer el relato que San Agustín hace de su conversión.

He aquí el relato de Santa Teresa: ${ }^{16}$

Como comencé a leer las Confesiones, paréceme me veía yo allí. Comencé a encomendarme mucho a este glorioso santo. Cuando llegué a su conversión y leí cómo oyó aquella voz en el huerto, no me parece sino que el Señor me la dio a mí, según sintió mi corazón. Estuve por gran rato que toda me deshacía en lágrimas y entre mi misma con gran aflicción y fatiga... Sea Dios alabado, que me dio vida para salir de muerte tan mortal. Paréceme que ganó grandes fuerzas mi alma de la Divina Majestad y que debía oír mis clamores y haber lástima de tantas lágrimas.

La forma pura de lo divino concretado en esta valoración intrinseca es el núcleo de la experiencia religiosa. En la religión cristiana se expresa por medio de la noción de "encarnación", por la cual el Verbo se hizo carne (Juan I, 14). De aquí que la experiencia de Jesús, para el místico de tipo más intelectual, sea de forma pura. Esta forma nada tiene que ver con cualquier forma material, no es forma en absoluto en el sentido del mundo, los órganos de la vista y el oído o aun el "órgano del alma", el "ojo interno", etc., todos los cuales son meras analogías. Desde el punto de vista de los sentidos, las formas contempladas en la experiencia del espíritu son informes. Sin embargo, en sí mismas están claramente definidas y estructuradas; sólo que esta estructura intrínseca no tiene semejanza con nada de lo visto en el mundo material (justo del modo, digamos; que la fórmula del oleaje no tiene semejanza con éste). De aquí que Angela de Foligno hable, en sus Consolaciones, con toda justicia de "visión informe". Empero, tal visión se refiere a un objeto mucho más agudamente definido y claramente aprehendido que cualquier forma material. "Cuando Dios viene al alma - escribe - algunas veces le permite contemplarlo; y lo contempla sin figura ni forma corporales y más claramente de lo que un hombre ve a otro. Pues los ojos del alma contemplan una presencia espiritual y no corporal, de la cual no soy capaz de hablar porque me fallan las palabras y la imaginación. En verdad, el alma se goza en tal visión con gozo inefable y no ve nada más, pues es esto lo que la llena de satisfacción inextinguible." ${ }^{17}$

17 Evelyn Underhill, Mysticism, Nueva York, 1911, pág. 339. 
Cuando Cristo aparece en esta forma puramente sistemática del espíritu, el místico es incapaz de describir esta experiencia "informe" de la forma espiritual que, sin embargo, está estructurada exactamente.

Ésta es la manera en la que Santa Teresa trata de describirla: ${ }^{18}$

Estando un día del glorioso San Pedro en oración, vi cabe mí o sentí, por mejor decir, que con los ojos del cuerpo ni del alma no vi nada, mas parecíame que estaba junto cabe mi Cristo y veía ser Él el que me hablaba, a mi parecer. Yo, como estaba ignorantísima de que podía haber semejante visión, dióme gran temor al principio y no hacía sino llorar, aunque en diciéndome una palabra sola de asegurarme, quedaba como solía, quieta y con regalo y sin ningún temor. Parecíame andar siempre a mi lado Jesucristo, y como no era visión imaginaria, no veía en qué forma; mas estar siempre al lado derecho, sentíalo muy claro, y que era testigo de todo lo que yo hacía, y que ninguna vez me recogiese un poco o no estuviese muy divertida po. día ignorar que estaba cabe mí. Luego fui a mi confesor harto fatigada a decírselo. Preguntóme en qué forma le veía. Yo le dije que no le veía. Díjome que cómo sabía yo que era Cristo. Yo le dije que no sabía cómo, mas que no podía dejar de entender estaba cabe mí... así no hay términos para decirlo acá las que poco sabemos, que los letrados mejor lo darán a entender. Porque si digo que con los ojos del cuerpo ni del alma no lo veo, porque no es imaginaria visión, ¿cómo entiendo y me afirmo con más claridad que está cabe mí que si lo viese? Porque parecer que es como una persona que está a oscuras, que no ve a otra que está cabe ella, o si es ciega, no va bien. Alguna semejanza tiene, mas no mucha, porque siente con los sentidos o la oye hablar o menear o la toca. Acá no hay nada de esto, ni se ve oscuridad; sino que se representa por una noticia al alma más clara que el sol. No digo que se ve sol ni claridad, sino una luz que, sin ver luz, alumbra el entendimiento, para que goce el alma de tan gran bien. Trae consigo grandes bienes.

Las visiones no son la única apariencia que acompaña la valoración intrínseca del pensamiento sistemático. Saulo de Tarso, Juana de Arco y otros oyeron las palabras que habrían de lanzarlos a su misión. Sin embargo, en la mayoria de los casos, estas voces iban acompañadas de visiones de luz.

Saulo, respirando amenazas de muerte contra los discípulos del Señor, se llegó al sumo sacerdote, pidiéndole cartas de recomendación para las sinagogas de Damasco, a fin de que si alli hallaba quienes 
siguiesen este camino, hombres o mujeres, los llevase atados a Jerusalén. Estando ya cerca de Damasco, de repente se vio rodeado de una luz del cielo; y cayendo a tierra oyó una voz que le decía: Saulo, Saulo, ¿por qué me persigues? Él contestó: ¿Quién eres, Señor? Y El: Yo soy Jesús, a quien tú persigues. Levántate y entra en la ciudad, y se te dirá lo que has de hacer.

Los hombres que le acompañaban quedaron atónitos oyendo la voz, pero sin ver a nadie. Saulo se levantó de tierra, y con los ojos abiertos nada veia. Lleváronle de la mano y le introdujeron en Damasco, donde estuvo tres días sin ver y sin comer ni beber. (Hechos IX, 1-9.)

He aquí cómo describe Juana de Arco su experiencia durante su juicio:

Contaba yo trece años cuando Dios envió una voz para guiarme. Al pronto me atemoricé mucho. La voz vino hacia el mediodía, en el verano, en el huerto de mi padre. Yo había ayunado el día anterior. Ó́ la voz a mi derecha, en dirección a la iglesia. Rara vez la oigo sin ver una luz. Esa luz aparece también del lado del que oigo la voz.

En todos estos casos, nos encontramos con la valoración intrínseca de símbolos, acompañada por la excitación de la experiencia, desde las lágrimas de angustia y desesperación hasta el rapto del éxtasis y el arrebatamiento. Todos estos fenómenos son considerados como "anormales" por los psicólogos, ya que ellos sólo consideran "normales" las experiencias sensibles. Pero para el axiólogo, estos fenómenos son las valoraciones intrínsecas normales del hecho interno del pensamiento simbólico. ${ }^{19}$

Tales experiencias no se limitan al campo de la religión. Aparecen, casi de modo idéntico, en el arte. El artista ve y oye en su mente la forma total de su obra artística, ya sea antes o después de su creación. Existe una valiosa carta de Mozart que muestra cómo toma forma una composición dentro de él, cómo la ve completa de un solo golpe y cómo esta forma es tan peculiarmente suya como su larga y torcida nariz.

Me preguntáis cuál es mi método para escribir y elaborar mis largas y pesadas cosas. De hecho, no puedo decir más que esto sobre el asunto: ni yo mismo lo sé y no he podido saberlo. Cuando me encuentro en condiciones particularmente buenas, quizá paseando en un carruaje o caminando después de una buena comida y también en una noche sin sueño, los pensamientos se me presentan de golpe.

19 Para detalles sobre las "Voces y visiones" véase Evelyn Underhill, Mysticism, parte II, cap. v. 
Cómo y dónde, eso no lo sé y no he podido saberlo. Los que me placen más, los retengo en la mente y los canturreo para mí mismo - cuando menos así me lo han dicho otros. Si me mantengo en ellos, pronto aparecen uno tras otro como útiles trozos para la obra, según el contrapunto, armonía de los diferentes instrumentos, etc., etc. Esto inflama mi espíritu, a no ser que esté perturbado. Sigue creciendo y yo continúo ampliándolo y haciéndolo cada vez más claro y la cosa, por larga que sea, llega a estar casi completa en mi cabeza, de tal modo que después puedo verla de un solo golpe, como un buen cuadro o un hombre apuesto, y en la imaginación la oigo no en sucesión, como deberá oírse después, sino como un todo simultáneo. Esto sí que es un regocijo. Todo este encontrar y crear ocurre en mi como un sueño muy vivido. Pero el ensayo - todo junto- es lo mejor de todo. Lo que así ha surgido no lo olvido con facilidad y es quizá el mejor de los dones que el Señor me ha dado. Cuando después me pongo a escribir, lo voy sacando del saco de mi cerebro que lo ha recogido del modo antes dicho. Así, pues, pasa muy rápidamente al papel; pues, como ya he dicho, está ya terminado; es más, muy rara vez será diferente de lo que ya tenía antes en mente. Por ello, puede distraérseme cuando escribo y toda clase de cosas puede ocurrir a mi alrededor, que yo seguiré escribiendo; hasta puedo hablar, al tiempo, de gallinas y gansos o de Fulano o Zutano, etc. Ahora bien, con respecto a mis obras, todo en ellas asume la forma o manera mozartiana y no el estilo de otro, justo del mismo modo que mi nariz es tan larga y torcida que se ha hecho mozartiana y no como la de la demás gente.

Aun un pintor valora intrínsecamente una forma sistemática interna, tal como una línea geométrica, una curva, una superficie, un espacio. Estas formas cognitivas internas son diferentes de sus ejemplos en el espacio y el tiempo, son formas que pertenecen por entero a la intuición. Por ejemplo, una línea geométrica tiene sólo una dimensión. Pero una línea sobre un papel o pizarrón tiene tres dimensiones, tiene un cierto ancho y un cierto grosor, sea ya de tinta, gis o cualquier otro material. El artista ve líneas y superficies en su mente y vuelca su propio yo en ellas. Entonces estas líneas asumen la vida del artista y, en su estado consciente valorativo, empiezan a tener vida, movimiento y vitalidad propios, formando una gran variedad de figuras que parecen representar las formas de toda creación. Empero, el proceso es reversible y las formas y curvas creadas aparecen como líneas geométricas y como símbolos de formas similares en otros seres. Así, Rodin veía "insectos, pájaros y peces" en un cuerpo femenino. Ningún artista ha 
tenido mayor conciencia del proceso de valoración intrínseca de lo geométrico que Rodin.

No soy un soñador —afirmó-, sino un matemático y mi escultura es buena porque es geométrica. Todo se obtiene siguiendo la naturaleza. Cuando tengo ante mí, como modelo, un bello cuerpo de mujer, los dibujos que hago de él me dan también imágenes de insectos, pájaros y peces. Lo que parece increíble e ignoraba yo mismo hasta descubrirlo... Una mujer, una montaña o un caballo están formados de acuerdo con los mismos principios... El cuerpo humano es como un templo en movimiento. Lo mismo que un templo tiene un punto central en torno al cual se pone y expande el volumen. Una vez que se ha entendido esto, se sabe todo... Me agradan ciertos símbolos. Veo las cosas desde un punto de vista simbólico... Al principio hacía estudios detallados según la naturaleza... después comprendí que el arte requiere más amplitud... por medio de una ampliación razonable del modelado. También éste consiste en la reducción constante del hecho a figura geométrica... El modelar según la naturaleza es copiar de la manera más exacta y, sin embargo, no tiene movimiento ni elocuencia. El arte aparece exagerando ciertos planos y afinando otros. En la escultura todo depende del modo en que se hace el modelado, se encuentra la línea activa del plano y se ejecutan los huecos y proyecciones... No me importa que se me llame simbolista, si con ello se define el principio esencial de la escultura, que es el modelado único que permite alcanzar la intensidad y amplia variedad del movimiento y el carácter. Si pudiéramos imaginar el pensamiento de Dios al crear el mundo, nos encontrariamos con que primero pensó el modelado, que es el principio único de la Naturaleza y, quizá, de los planetas. ${ }^{20}$

Rodin, escribe Story, "acostumbraba contemplar amorosamente sus creaciones $\mathrm{y}$, algunas veces, parecía quedar atónito y absorto ante la idea de haberlas creado, hablando de ellas como si tuvieran una existencia aparte de la de él... Las amaba, penetraba en sus vidas abstractas y tenía obligaciones morales con respecto a ellas. Eran su única preocupación... Tenía menos fe en los individuos que en las ideas generales. Tenía tanta devoción por su obra que sólo toleraba, con un aburrimiento cortés, lo demás y tenía horror a las discusiones o a que se le perturbara. Sus estatuas eran las estatuas de su alma. Parecía estar obsesionado con una especie de locura divina por la forma". 21

20 S. Story, Auguste Rodin, Nueva York, 1939, págs. 14 s.

21 Story, op. cit., págs. 11, 26. 
Es ésta una expresión de la valoración intrínseca de formas cognitivas sistemáticas. Rodin sabía tan bien que estas formas eran cognitivas como lo sabía Leonardo da Vinci, pongamos por caso (su Tratado de pintura presenta un sistema de clasificación de la forma humana, dividiendo, por ejemplo, el rostro en cuatro partes: frente, nariz, boca y barbilla, y mostrando las diversas formas que pueden tomar, por ejemplo, doce formas de nariz). La ejecución de estas formas en figuras externas era, para Rodin, un asunto de comprensión sistemática exacta y no de sentimiento o inspiración. Para él, la inspiración significaba la dedicación total a la obra - valoración intrínseca. La obra misma era asunto de aplicación. "Advertía a los jóvenes que no se fiasen de la inspiración y les decía que nada lograrían a no ser por un trabajo arduo. En efecto, en años posteriores tendía a menospreciar el papel de la inspiración en la obra artística y le daba, despreciativamente, el nombre de 'un sueño'. Para él el trabajo era la verdadera religión. Según Rodin, la inspiración era otra cosa; gustaba de mantener junto a sí una obra mucho tiempo después de que otros la hubieran considerado terminada y dar algunos toques aquí y allá, sugeridos por súbitas ideas de mejoramiento. Se le ha comparado con uno de esos artífices anónimos de la Edad Media que pasaron sus vidas esculpiendo las figuras de una catedral." 22

Este trabajo continuo es necesario a fin de llevar la forma interna valorada intrínsecamente al mundo exterior. Este último es la valoración extrínseca de la valoración intrínseca de la pura forma cognitiva. Esta forma puede aplicarse a cosas aparentemente concretas. El artista disuelve las cosas concretas en formas abstractas. Valora así lo extrínseco sistémicamente como un ejercicio que precede a la valoración intrínseca de estas formas sistemáticas. A pesar de que estas formas son hechos internos, pueden ser sugeridas por cosas del espacio y el tiempo o reducidas a partir de ellas. Es éste un proceso de valoración sistémica de la percepción que debe ser examinado en su lugar. Pero será conveniente dar un ejemplo aquí.

La pintura trata un poco más concretamente con la abstracción [que la música], por representar simbólicamente muchos de los aspectos tangibles de la realidad y disolverlos por implicación en el flujo rítmico de la ideación esencial. La pintura trata de la apariencia de las cosas, que es, quizá, lo más cercano, después del tacto, al modo instintivo de percepción del hombre. Trata, en forma muy literal, de la apariencia y en su grado más sutil de creación disuelve todas las ilusiones de apariencia y revela parte de la realidad subyacente. El físico nos dice y nos "muestra" matemáticamente que una silla no es más sustancial que las ondas vibratorias de energía que 
componen su naturaleza atómica. El pintor relaciona su experiencia de una silla con su experiencia del espacio y de las sustancias aparentes en torno suyo y, después... relaciona toda la experiencia con él mismo... Uno de los modos en que el pintor revela su intuición de esta "naturaleza ilusoria de la sustancia" es por la eliminación de los contornos estáticos de los objetos que la humanidad ha llegado a aceptar automáticamente como verdaderos... Las manzanas sobre una mesa vistas por un lego y por un artista presentan todo un mundo de diferencia en el concepto. El lego cataloga en su mente las distintas figuras en su asociación mutua y con la mesa, ${ }^{23}$ y retiene un sentido de identidades separadas cuya única relación es de cercanía o aun de continuidad. Toda una multitud de malos hábitos intelectuales, formados a través de la historia del desarrollo humano, le impide a cualquier mentalidad que no sea la más intuitiva el ver mejor, el ver más verdaderamente... Si fuéramos a reducir el concepto que un artista tiene de varias manzanas sobre una mesa a términos verbales, que nunca usó conscientemente para pensarlas, diríamos que reconoce las manzanas, el espacio en el que están y la mesa en la que descansan como algo que consta en última instancia de la misma clase de impulsos eléctricos inmateriales. De aquí que conciba todas estas figuras como ilusiones mientras parezcan estar separadas. Se da cuenta de que no existe cosa tal como una línea real que circunscriba cualquiera de estas manzanas, aislándola. También se da cuenta de que, dentro de su propia experiencin, que es para él la conciencia más real accesible, estas manzanas fluctúan en la intensidad de su aparente realidad, lo que depende del todo de su vista y sentido del tacto. Si ve la manzana $A$, las manzanas $B, C$ y $D$ se retiran a una perceptibilidad secundaria. Intelectualmente sigue atribuyendo una realidad igual a todas ellas. Pero plásticamente avanzan y retroceden en importancia, en "realidad", según se aproximan o alejan de la atención del contemplador. La impresión final de un cuadro completamente acabado es similar a la impresión que tiene una mente matemática cuando contempla visiones de totalidad, tal como son aprehendidas por medio de constelaciones limitadas de partes. ${ }^{24}$

Este ejemplo muestra la manera en la que los hechos internos difieren de los externos y cómo el artista puede apropiarse las formas de la imaginación a partir de la percepción sensible.

La valoración intrínseca de formas sistemáticas internas aparece no sólo

23 Ésta es la valoración extrínseca de valores extrínsecos.

24 Richard Guggenheimer, Sight and Insight, Nueva York, 1945, págs. $93 \mathrm{~s}$. 
en la religión y en el arte, sino también en las matemáticas y la ciencia. Daremos ahora un ejemplo de las matemáticas; muestra tanto el júbilo como la naturaleza perceptiva de una forma tan abstracta como lo es una prueba matemática.

Estaría de acuerdo con esta curiosa afirmación de Daunou: "En la ciencia, aun en la más rígida, no nace ninguna verdad del genio de un Arquímedes o un Newton sin una emoción poética y sin cierto temblor de naturaleza intelectual"... Así, Gauss escribe, refiriéndose a un teorema aritmético que había tratado de probar, sin éxito, durante años: "Por fin, hace dos días, lo logré, no por mis penosos esfuerzos, sino por gracia de Dios. Como en un relámpago súbito, el enigma quedó resuelto. Soy incapaz de decir cuál fue el hilo conductor que conectó lo que ya sabía con lo que hizo posible mi buen éxito"... De cierto, el verdadero proceso de pensamiento para construir un argumento matemático puede compararse con... el acto de reconocer a una persona. Un caso intermedio que ilustra la analogía entre los dos procesos puede encontrarse en los estudios psicológicos de jugadores de ajedrez, algunos de los cuales, como se sabe, pueden jugar diez o doce juegos simultáneos sin ver los tableros. Se iniciaron estudios, en especial Alfred Binet, para ver cómo era esto posible: sus resultados pueden resumirse diciendo que para muchos de estos jugadores cada juego tiene, por asi decirlo, una especie de fisonomia que le permite pensarlo como una cosa unica, por complicado que pueda ser, tal como vemos el rostro de un hombre... De modo semejante, cualquier argumento matemático, por complicado que sea, se me aparece como una cosa única. No siento que lo he comprendido mientras no logro apresarlo en una idea global... Tomemos una prueba elemental y muy conocida en la aritmética, por ejemplo, el teorema: "La secuela de los números primos es ilimitada." Repetiré los pasos sucesivos de la prueba clásica de tal teorema, escribiendo, frente a cada uno de ellos, la imagen mental que le corresponde en mi mente. Por ejemplo, tenemos que probar que hay un número primo mayor que 11 .

\section{Pasos de la Prueba}

Considero todos los números primos de 2 a 11 , digamos, 2 , $3,5,7,11$

Formo su producto $2 \times 3 \times 5 \times 7 \times 11=N$
Mi Imagen Mental

Veo una masa confusa

Por ser $\mathrm{N}$ un número grande, imagino un punto bastante remoto de la masa confusa 
Aumento en 1 tal producto, digamos, $\mathrm{N}+\mathbf{1}$

Tal número, si no es primo, debe admitir un divisor primo, que es el número buscado
Veo un segundo punto algo más atrás del primero

Veo un lugar entre la masa confusa y el primer punto

Fácilmente puede verse cómo tal mecanismo, o uno análogo, puede serme necesario para comprender la prueba anterior. Lo necesito a fin de tener una vista simultánea de todos los elementos del argumento, para mantenerlos unidos, para hacer un todo de ellos - en resumen, para lograr esa síntesis de la que hablamos al principio de la sección y dar su fisonomía al problema. ${ }^{25}$ ticos:

Ahora un ejemplo de la ciencia, que nos recuerda las voces de los mís-

Tras una intensa concentración y muchos vanos esfuerzos para salvar esta dificultad (relacionada con la determinación de las constantes de ionización sucesivas para el hidrógeno del ácido orto y pirofosfórico), decidí contra mi voluntad abandonar el método. Estaba cansado, descorazonado y hambriento... Liberé mi mente de todo pensamiento del problema y caminé animosamente por Tremont Street (Boston) cuando de pronto, en un sitio que puedo localizar hoy, surgió en mi mente esta idea, tan claramente como si alguien le hubiese gritado estas palabras: "En farmacia y en la industria clarificamos las emulsiones por medio de un centrífugo de alta velocidad; tal método sería impráctico en un termostato. Pero si la giración rápida logra hacerlo por un breve lapso, «por qué una lenta rotación, durante un periodo más prolongado, no ha de lograr los mismos resultados?" 26

Parecería que sólo las formas cognitivas extraordinarias podrían ser valoradas intrínsecamente. Pero cualquiera que haya tratado de encontrar un nombre para su hijo o haya pensado en el nombre de la amada sabe que no hay forma - ni aun los nombres corrientes- que no pueda ser valorada de este modo. Esto es válido no sólo acerca de los nombres propios, sino también acerca de los nombres genéricos de las cosas - aun cuando se necesiten circunstancias y ocasiones especiales para producir la valoración intrín-

25 J. Hadamard, The Psychology of Invention in the Mathematical Field, Princeton, 1945 , págs. $10,15,65,76 \mathrm{~s}$.

26 E. D. Hutchinson, How to Think Creatively, Nueva York, 1949, págs. 143 s. Acerca de las emociones producidas por la creación, véase el cap. vi de esta obra, en especial las págs. $162 \mathrm{~s}$. 
seca de simples palabras de uso corriente. A continuación damos un famoso ejemplo de tal valoración, tomado de la autobiografía de Helen Keller:

Un día, mientras jugaba con mi muñeca nueva, la señorita Sullivan puso en mi regazo mi gran muñeca de trapo, deletreó "m-u-ñ-e-c-a" y trató de hacerme entender que "m-u-ñ-e-c-a" se aplicaba a las dos. La señorita Sullivan había intentado hacerme comprender que " $\mathrm{j}$-ar-r-a" es jarra y que "a-g-u-a" es agua, pero yo seguía confundiendo las dos. Desesperada había abandonado el asunto por un tiempo, si bien pensaba volver a él en la primera oportunidad... Caminamos por el sendero hacia el pozo, atraídas por la fragancia de la madreselva que lo cubría. Alguien sacaba agua y mi maestra puso mi mano bajo el chorro. Mientras la fría corriente resbalaba por una mano, deletreó en la otra la palabra agua, primero lentamente y después con rapidez. Permanecí quieta, toda mi atención fija en los movimientos de sus dedos. De pronto sentí una vaga conciencia como de algo olvidado - la emoción de un pensamiento que vuelve; y de algún modo se me reveló el misterio del lenguaje. Supe entonces que "a-g-u-a" significaba ese frío y maravilloso algo que corría por mi mano. Esa palabra viva despertó mi alma, le dio luz, esperanza, alegría, la liberó. Todavía había barreras, es verdad, pero barreras que podrían desaparecer con el tiempo. Dejé el pozo ávida de aprender. Todo tenía un nombre y cada nombre hacía nacer un nuevo pensamiento. Mientras volvíamos a casa, todos los objetos que tocaba parecían vibrar de vida. Esto se debía a que veía todo con la extráña y nueva vista que se me había dado... Aprendí muchas nuevas palabras ese día. No recuerdo cuáles eran; pero sí sé que madre, padre, hermana, maestra estaban entre ellas - palabras que harian que el mundo floreciera para mí, "como la vara de Aarón, había echado flores". Habría sido difícil encontrar un niño más feliz que yo cuando, al término de ese día memorable, me encontraba en mi cuna y repasaba las alegrías que me había traído y, por primera vez, deseaba que llegara el nuevo día. ${ }^{27}$.

Tenemos aquí todas las características de la valoración intrínseca de una forma cognitiva. El místico no se siente más arrebatado por su visión del Reino de Dios de lo que Helen Keller se sintió por su visión del universo del lenguaje.

He aquí el relato que la maestra de Helen, Ann Sullivan, hace del mismo suceso.

27 Helen Keller, The Story of My Life, Nueva York, 1905, págs. 22 ss. 
Debo escribirle unas líneas esta mañana, ya que ha sucedido algo muy importante. Helen ha dado el segundo gran paso hacia su educación. Ha aprendido que todo tiene un nombre y que el alfabeto manual es la clave de todo lo que desea saber... Esta mañana, mientras se lavaba, quiso saber el nombre del "agua". Cuando desea saber el nombre de algo, lo señala y golpea mi mano. Deletreé "a-gu-a" en la mano libre de Helen. La palabra, que vino tan rápidamente después de la sensación del agua fría que corría por su mano, pareció sorprenderla. Dejó caer la jarra y quedó como atónita. Una nueva luz cayó sobre su cara. Deletreó "agua" varias veces. Después se dejó caer a tierra y preguntó por su nombre, señaló la bomba y el enrejado y de pronto, girando, preguntó mi nombre. Deletreé "maestra". Durante el camino de regreso a casa estuvo muy excitada y aprendió el nombre de todos los objetos que tocaba, de modo que en unas cuantas horas añadió treinta palabras a su vocabulario. A la mañana siguiente se levantó como un hada radiante. Revolotea de un objeto a otro, preguntando el nombre de todo, y me besa de pura alegría... Todo debe tener un nombre ahora. A dondequiera que va, pregunta ansiosamente por el nombre de las cosas que no ha aprendido en casa. Desea vivamente que sus amigos le deletreen y quiere enseñar las letras a todo el que encuentra. Ha dejado de usar los signos y pantomimas de que se valía antes, tan pronto como tiene las palabras que lo suplan, y la adquisición de una nueva palabra le produce el más vivo placer. Advertimos que su cara es cada día más expresiva. ${ }^{28}$

Esta valoración intrínseca de los nombres fue dramática en el caso de Helen Keller sólo por sus circunstancias extraordinarias (lo mismo puede decirse del caso de Laura Bridgman). Pero en todos los niños, el descubrimiento de los nombres da origen al mismo tipo de valoración intrínseca. Los niños viven estos nombres y se deleitan en ellos.

Hacia el principio del vigésimotercer mes -dice D. R. Majorel niño ha desarrollado una manía por poner nombres a las cosas, como si quisiera decir a los demás sus nombres o llamar la atención hacia las cosas que examina. Mira un objeto, lo señala o pone su mano sobre él y dice su nombre, después se vuelve a mirar a quien lo acompaña. ${ }^{20}$

28 Op. cit., págs. 315 ss.

20 David R. Major, First Steps in Mental Growth, Nueva York, 1906, págs. 321 s. E. Cassirer, An Essay on Man, New Haven, Conn., 1944, pág. 192. [Trad. esp.: Antropologia filosofica, México, 1945.] 
Estos ejemplos aclararán la presencia universal de un fenómeno de valor, al parecer tan esotérico, como la valoración intrínseca de los hechos sistemáticos internos. Muestra la riqueza de este tipo de valoración -que, a su vez, es sólo una pequeña parte del gran tema de la valoración de los hechos internos. La articulación de este tema habrá de traer una nueva luz sobre la relación, tan vaga y oscura actualmente, entre el valor y el sentimiento.

Robert S. HARTMAN

Centro de Estudios Filosóficos

Universidad Nacional Autónoma de México 